\title{
Fighting Liver Fibrosis with Naturally Occurring Antioxidants
}

Authors

Ligen Lin, Fayang Zhou, Shengnan Shen, Tian Zhang

\section{Affiliation}

State Key Laboratory of Quality Research in Chinese Medicine, Institute of Chinese Medicine Sciences, University of Macau, Macau, China

Key words

liver fibrosis, antioxidants, oxidative stress, reactive oxygen species, hepatic stellate cells, natural products

\author{
received August 3, 2018 \\ revised September 24, 2018 \\ accepted October 7, 2018
}

Bibliography

DOI https://doi.org/10.1055/a-0757-0008

Published online October 12, 2018 | Planta Med 2018; 84: 1318-1333 @ Georg Thieme Verlag KG Stuttgart · New York | ISSN 0032-0943

Correspondence

Dr. Ligen Lin

Institute of Chinese Medical Sciences, University of Macao, Room 6044, Research Building N22

Avenida da Universidade, Taipa, Macau 999078, China

Phone: + 85388228041 , Fax: + 85328841358

ligenl@umac.mo

\section{ABSTRACT}

Liver fibrosis is a wound-healing response characterized by the accumulation of extracellular matrix following various liver injuries, which results in the deformation of the normal liver architecture and the development of liver cirrhosis and even hepatocellular carcinoma. Numerous in vitro and in vivo studies indicated that oxidative stress mediates the initiation and progression of liver fibrosis. Overaccumulation of reactive oxygen species disrupts macromolecules, induces necrosis and apoptosis of hepatocytes, stimulates the production of pro-fibrogenic mediators, and directly activates hepatic stellate cells, thereby resulting in liver damage and initiating liver fibrosis. Ameliorating oxidative stress is a potential therapeutic strategy for the treatment of liver fibrosis. Natural antioxidants have attracted increasing attention in treating liver fibrosis due to their safety and efficacy. In this review, the pathogenesis of liver fibrosis and the role of oxidative stress in liver fibrosis were discussed. Naturally occurring antioxidants that can treat and prevent liver fibrosis were summarized. Advances in clinical trials were also presented. The main purpose of this review is to provide a comprehensive and upto-date knowledge from the biological importance of oxidative stress in liver fibrosis to representative antioxidants for treating liver fibrosis. Naturally occurring antioxidants show a potential for further investigations as lead compounds in fighting liver fibrosis.

\section{Introduction}

Liver diseases, including chronic hepatitis, steatosis, fibrosis, cirrhosis, and hepatocellular carcinoma (HCC), have become continuous and increasing threats for public health [1-5]. Liver fibrosis is a wound-healing process during liver injury caused by viral infection, inflammatory response, high lipid diet, drugs, environmental pollutants, excessive alcohol intake, and autoimmune response, which is characterized by the deposition of collagen and accumulation of extracellular matrix (ECM) [6, 7]. Liver fibrosis results in the deformation of the normal liver architecture, HCC, and ultimately liver failure that is accompanied by remarkable morbidity and mortality. Fibrotic diseases are a major cause of mortality in industrialized nations [8, 9]; therefore, anti-fibrotic therapies are urgently needed.

In this review, scientific studies from 1980 to 2018 were searched using Google Scholar, PubMed, Web of Science, and Scopus, with "liver fibrosis", "natural products", and "antioxidant" as keywords. Only English publications were selected. Herbal extracts without clear components and those with inadequate or insufficient data in terms of examination assays with controls are excluded as described in > Fig. 1. Review articles are also excluded. Thirty-five naturally occurring antioxidants with anti-liver fibrotic property from 57 studies were summarized in this review.

\section{The Pathogenesis of Liver Fibrosis}

Many factors, such as hepatic viral infection, excessive alcohol consumption and drug intake, and high-fat diet (HFD) feeding, can cause temporary (acute) or self-limited lesion in the liver, characterized by the induction of a focal inflammatory response, enzymatic evidence of liver damage, and hepatic necrosis and apoptosis [6]. Acute or self-limited lesion in the liver provokes ECM deposition and transiently changes the liver architecture for the sake of healing. These lesions are potentially reversible responses to the injury at the early stage of liver fibrosis. However, these situations could aggravate and develop into irreversible liver 


\begin{tabular}{|c|c|}
\hline \multicolumn{2}{|c|}{ ABBREVIATIONS } \\
\hline ALP & alkaline phosphatase \\
\hline ALT & alanine aminotransferase \\
\hline AMPK & AMP-activated protein kinase \\
\hline APAP & acetaminophen \\
\hline ARE & antioxidation response element \\
\hline AST & aspartate aminotransferase \\
\hline BDL & bile duct-ligated \\
\hline DEN & diethylnitrosamine \\
\hline DMN & dimethylnitrosamine \\
\hline DPPH & 2,2-diphenyl-1-picrylhydrazyl \\
\hline ECM & extracellular matrix \\
\hline EGCG & epigallocatechin gallate \\
\hline ET-1 & endothelin-1 \\
\hline FFA & free fatty acid \\
\hline$\gamma$-GCS & Y-glutamylcysteine synthetase \\
\hline GPx & glutathione peroxidase \\
\hline GR & glutathione reductase \\
\hline GSH & glutathione \\
\hline GSK-3 $\beta$ & glycogen synthase kinase $3 \beta$ \\
\hline GST & glutathione transferase \\
\hline HBV & hepatitis B virus \\
\hline $\mathrm{HCC}$ & hepatocellular carcinoma \\
\hline $\mathrm{HCV}$ & hepatitis C virus \\
\hline HFD & high-fat diet \\
\hline HO & heme oxygenase \\
\hline HSC & hepatic stellate cell \\
\hline ICR & Institute of Cancer Research \\
\hline iNOS & inducible NO synthase \\
\hline KEAP-1 & kelch-like ECH-associated protein-1 \\
\hline LPS & lipopolysaccharides \\
\hline MAO & monoamine oxidase \\
\hline MAPK & mitogen-activated protein kinase \\
\hline MDA & malondialdehyde \\
\hline MMP & matrix metalloproteinase \\
\hline NADPH & nicotinamide adenine dinucleotide phosphate \\
\hline NAFLD & nonalcoholic fatty liver disease \\
\hline NAS & NAFLD activity score \\
\hline NASH & nonalcoholic steatohepatitis \\
\hline NDMA & N'-nitrosodimethylamine \\
\hline NF-кB & $\begin{array}{l}\text { nuclear factor } \kappa \text {-light-chain-enhancer } \\
\text { of activated B }\end{array}$ \\
\hline NO & nitric oxide \\
\hline NQO1 & NAD(P)H quinine oxidoreductase 1 \\
\hline NRF2 & the nuclear factor erythroid 2-related factor 2 \\
\hline 3-NT & 3-nitrotyrosine \\
\hline OPN & osteopontin \\
\hline OS & oxidative stress \\
\hline PAI-1 & plasminogen activator inhibitor- 1 \\
\hline PCNA & proliferating cell nuclear antigen \\
\hline PDGF & platelet-derived growth factor \\
\hline ROS & reactive oxygen species \\
\hline$\alpha-S M A$ & $\alpha$-smooth muscle actin \\
\hline SOD & superoxide dismutase \\
\hline SP-1 & the specificity protein- 1 \\
\hline
\end{tabular}
TAA
thioacetamide
TBARS
TGF- $\beta 1$
TIMP
thiobarbituric acid reactive substances
transforming growth factor- $\beta 1$
VLDL-TG
tissue inhibitor of metalloproteinase
very-low-density lipoprotein-triglycerides

cirrhosis and ultimately into HCC with sustained liver injury and overaccumulation of ECM [7]. In normal liver, ECMs maintain a state of dynamic equilibrium [10]. To maintain the balance of production and degradation of ECM, matrix metalloproteinases (MMPs) are activated to remove the over-deposited ECM and protect the liver against irreversible harm. The TIMPs (tissue inhibitor of metalloproteinases) hinder the clearance of ECM, which worsens the situation ( $\vee$ Fig. 2) $[11,12]$. Hepatic stellate cells (HSCs), contributing to approximately $90 \%$ of ECM production in myofibroblasts, play a pivotal role during ECM generation and fibrotic scar formation ( $>$ Fig. 2) [13]. In normal conditions, HSCs store vitamin A, control the production of ECM, and regulate local vascular contractility, which are important functions in liver development, metabolism, immune response, and angiogenesis. Upon stimulation, quiescent HSCs are induced into activated HSCs, which are proliferating, fibrogenic, and contractile [13]. Cells derived from the bone marrow derived cells, including circulating fibrocytes and portal fibroblasts, are also transdifferentiate into fibrogenic myofibroblasts during liver injury ( $\bullet$ Fig. 2) [13].

Regulation of HSCs activation and ECM deposition is a potential strategy for the treatment of liver fibrosis $[7,14]$. A number of studies have proved the therapeutic agents suppressing HSC activation and ECM accumulation are promising for the treatment of liver fibrosis [15-17].

\section{Oxidative Stress in Liver Fibrosis}

Oxidative stress (OS) is a disturbance in the balance between the production of free radicals and antioxidant defenses and is involved in the pathogenesis of various liver diseases [18]. In liver, many factors, including chronic and excessive alcohol consumption [19], HFD [20], hepatic viral infection [21], and autoimmune response [22], contribute to the onset of OS. OS disrupts the structure and function of biologically relevant macromolecules such as nucleic acids, proteins, lipids, and carbohydrates. In hepatocytes, reactive oxygen species (ROS) are mainly generated by the electron transport chain in the mitochondria, in the endoplasmic reticulum during protein folding and detoxification by cytochrome P450 systems, in the lysosomes during the removal of damaged cellular components, and in the peroxisomes during metabolic or detoxification activities $[23,24]$. The prototypic nicotinamide adenine dinucleotide phosphate (NADPH) oxidase in the plasma membrane and phagosomes also contributes to the production of ROS in Kupffer cells [25]. When the intracellular antioxidant defense system is overwhelmed, excessive ROS induce liver dysfunction and injury to stimulate inflammatory responses and the infiltration of neutrophils [26]. Kupffer cells, endothelial cells, and infiltrating inflammatory cells then secrete transforming growth factor- $\beta 1$ (TGF- $\beta 1$ ) following the liver injury. The cross-talk 
between hepatocytes and HSCs is bidirectional. On the one hand, the injured hepatocytes, activated Kupffer cells, and infiltrating neutrophils generate excessive ROS and secrete inflammatory cytokines and TGF- $\beta 1$ to activate HSCs, which results in overproduction of ECM and the specific inhibitors of MMP, such as TIMP-1 and TIMP-2 [27, 28]. On the other hand, the activated HSCs produce ROS to destroy hepatocytes and activate Kupffer cells. In addition, TGF- $\beta 1$ induces its own expression in activated HSCs, thereby creating an autocrine loop [29].

Challenging with free radicals from cellular and xenobiotic metabolism and immune process, liver cells develop their enzymatic and non-enzymatic antioxidative defense systems (• Fig.3). Superoxide dismutase (SOD), glutathione peroxidase (GPx), glutathione reductase (GR), glutathione transferase (GST), heme oxygenase $(\mathrm{HO})$, and catalase are commonly involved in enzymatic antioxidant defense [30]. Some signaling pathways, including NF- $\kappa$ B (nuclear factor $\kappa$-light-chain-enhancer of activated B) and NRF2 (the nuclear factor erythroid 2-related factor 2)/HO-1, are involved in fighting against oxidative damage. The NF- $\kappa$ B subunits are oxidized by ROS, which impair the DNA binding and transcriptional activity of NF- $\kappa$ B. Its inhibitor $I_{\kappa} \mathrm{B} \alpha$ is degraded with the help of IKK kinase complexes [31]. Hence, the activation of IKK kinase activity is a potent strategy to enhance the NF- $\kappa$ B activity and strengthen its antioxidant capacity [32]. As a transcription factor, NRF2 dissociates from its inhibitor kelch-like ECH-associated protein-1 and binds to antioxidation response element (ARE) in nucleus to activate the transcription of its target genes, including $\mathrm{NAD}(\mathrm{P}) \mathrm{H}$ quinine oxidoreductase $1, \mathrm{HO}-1$, and $\gamma$-glutamylcysteine synthetase under OS [33].

Apart from the enzymatic antioxidant defense, some endogenous antioxidants, such as ascorbic acid (vitamin C), carotenoids, $\alpha$-tocopherol (vitamin E), and glutathione (GSH), participate in non-enzymatic antioxidant defense ( $\vee$ Fig. 3) [30]. Hence, antioxidants strengthening the cellular antioxidative capacity are promising strategies for treatment of liver fibrosis [18, 34].

\section{Antioxidants for the Treatment of Liver Fibrosis}

Considering that OS has been implicated in fibrogenic stimulation for decades and overaccumulation of ROS is a crucial part of fibrotic pathway, the application of antioxidants for the treatment of liver fibrosis has been well documented $[35,36]$. Recent findings contributed a concept of redox-fibrosis, in which the cellular oxidant and antioxidant systems could serve as potential therapeutic targets $[37,38]$. Several anti-fibrotic therapies aimed to modulate OS and the generation of ROS have been put forward, and some of them have already been involved in clinical trials [39]. The safety and efficacy of natural antioxidants have attracted increasing attention. Hence, naturally occurring antioxidants for the treatment of liver fibrosis and the potential mechanisms were summarized ( $\bullet$ Table $\mathbf{1})$.

\section{Flavonoids}

Flavonoids are a group of polyphenolic compounds with a C6-C3C6 core structure, and most flavonoids possess antioxidant

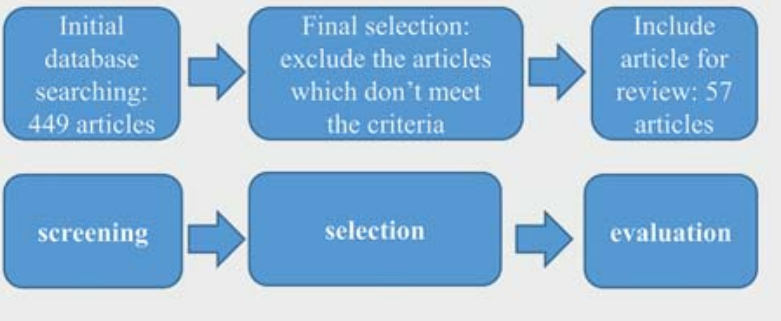

- Fig. 1 Criteria used to select the articles for the data presented in this review.

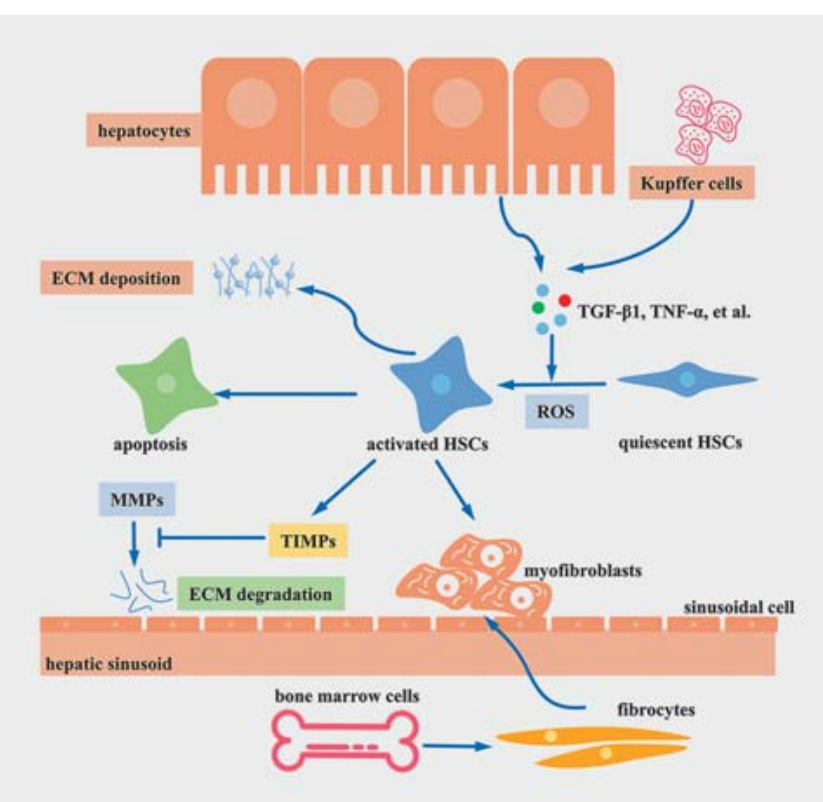

- Fig. 2 The general pathogenesis of liver fibrosis.

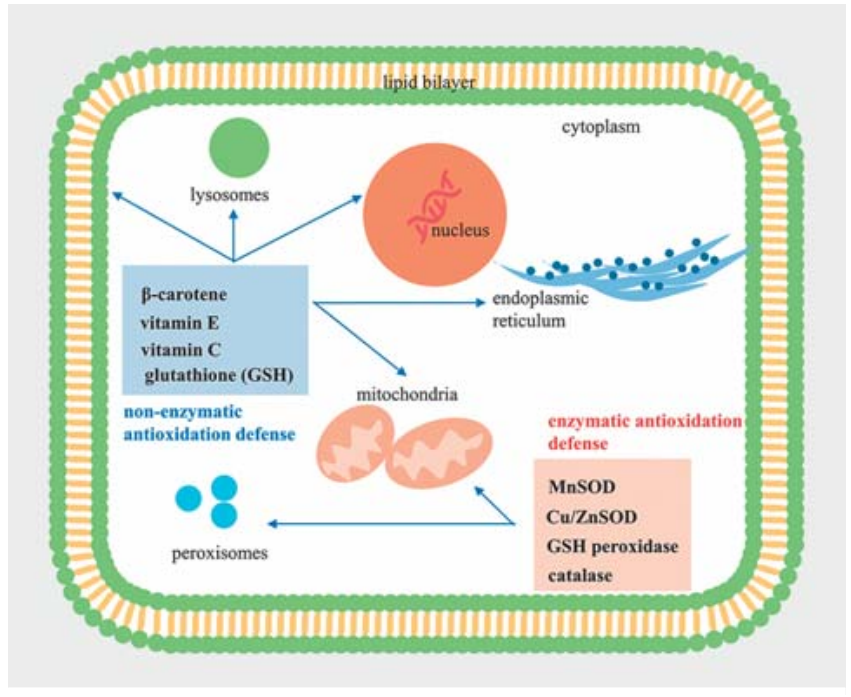

- Fig. 3 The non-enzymatic and enzymatic antioxidative defense systems. 


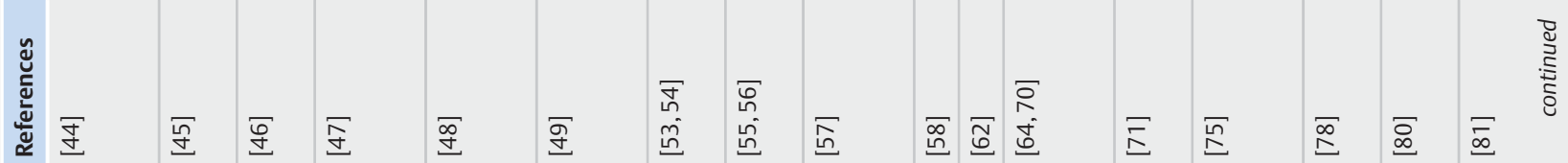

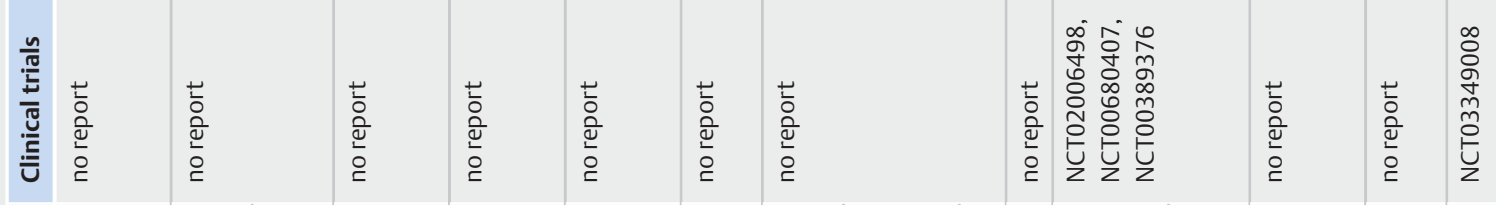

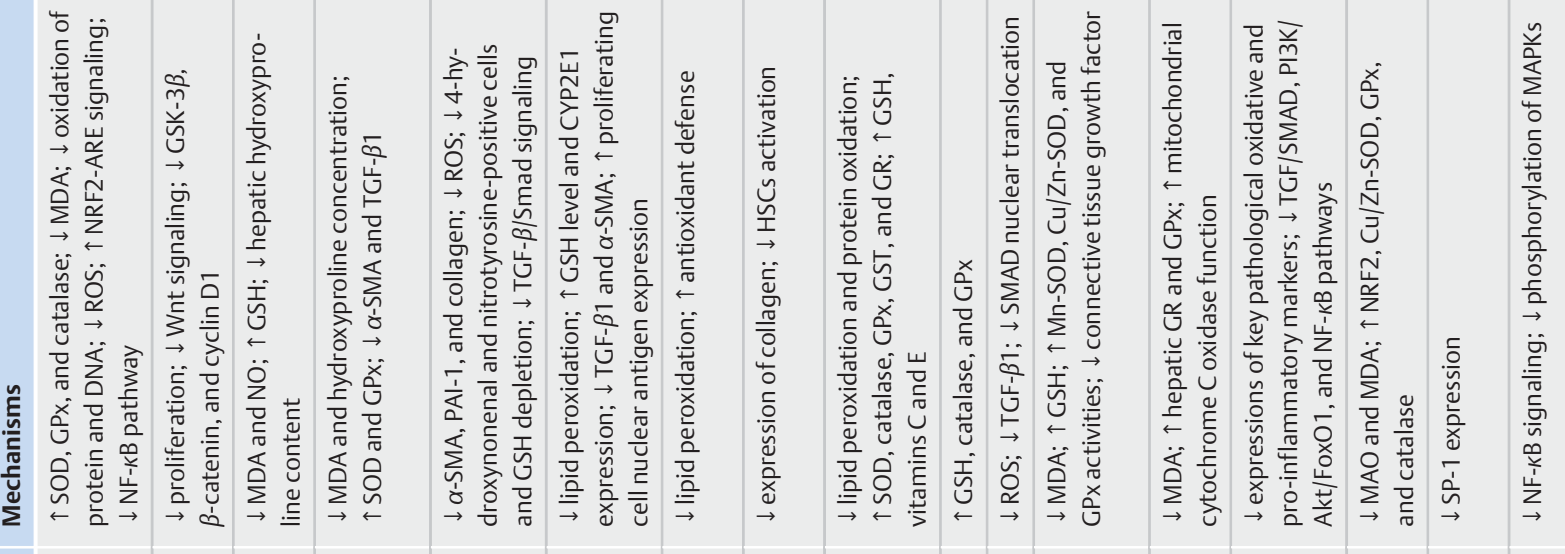

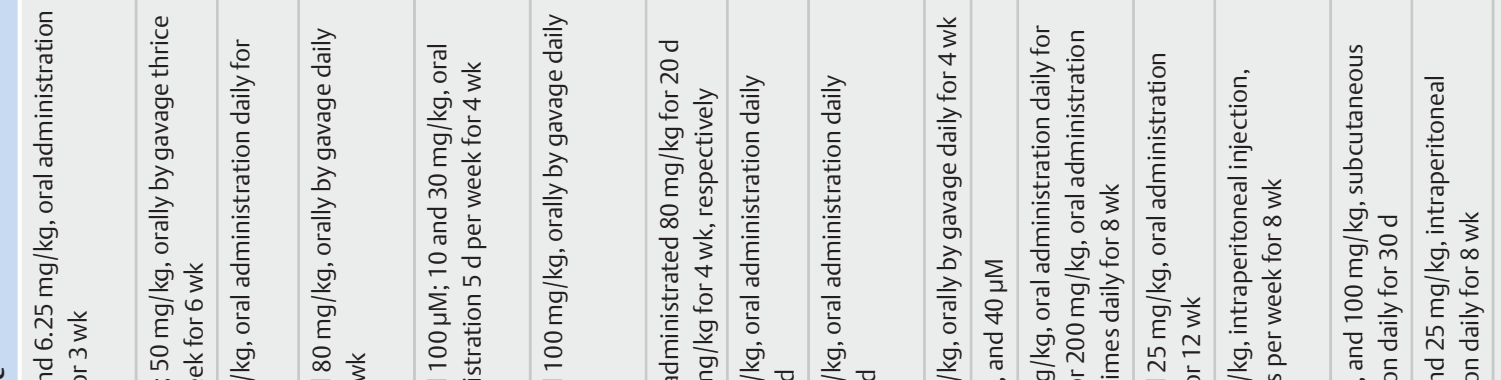

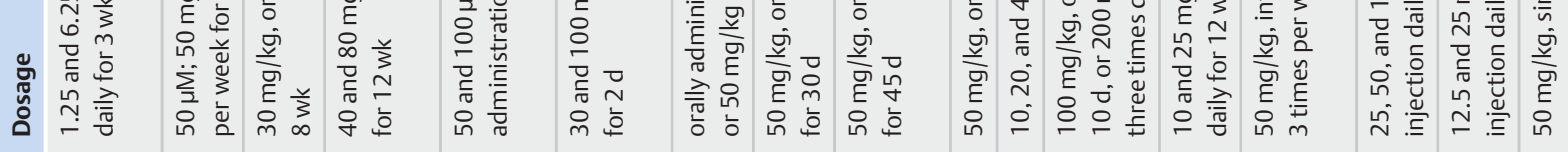

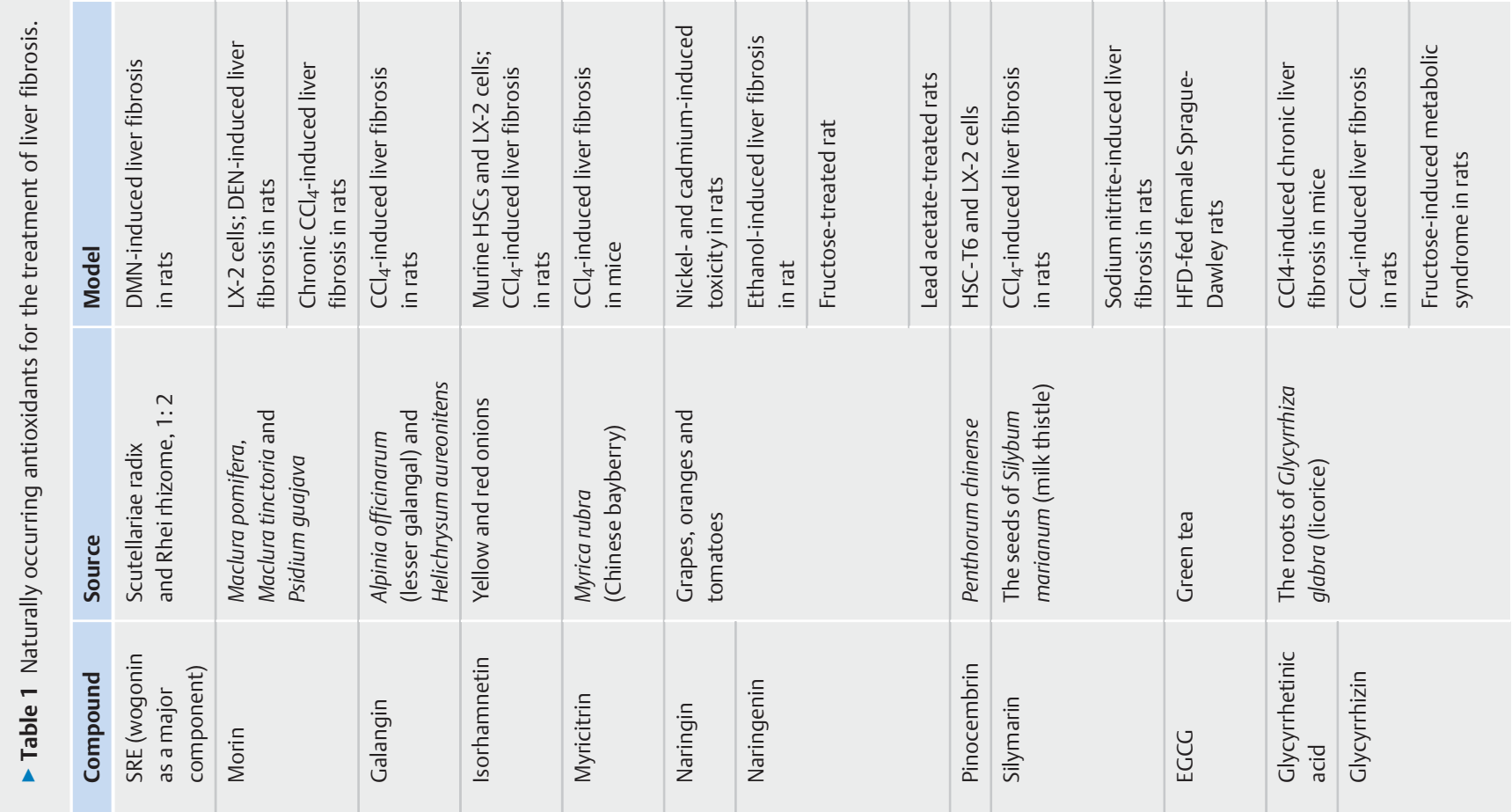




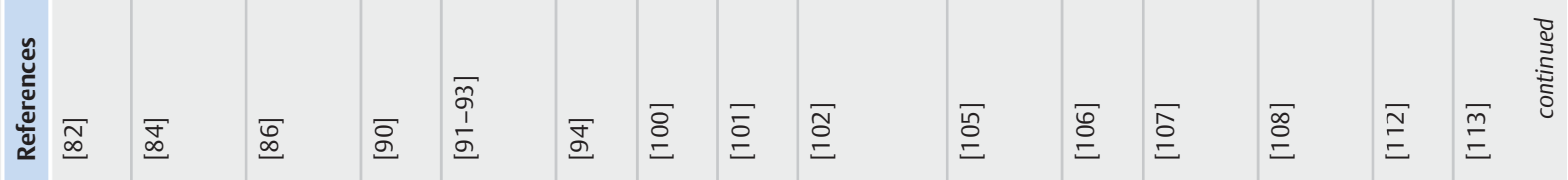

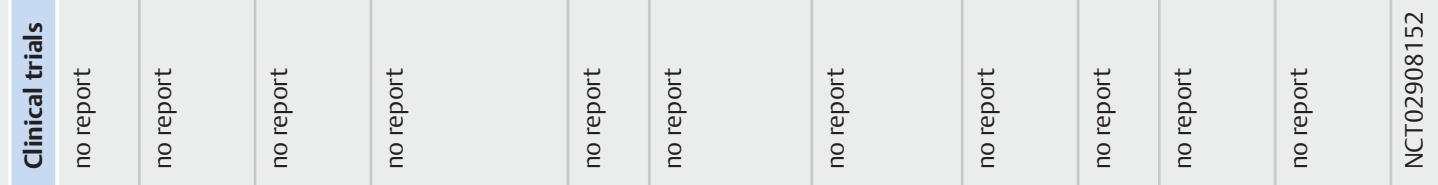

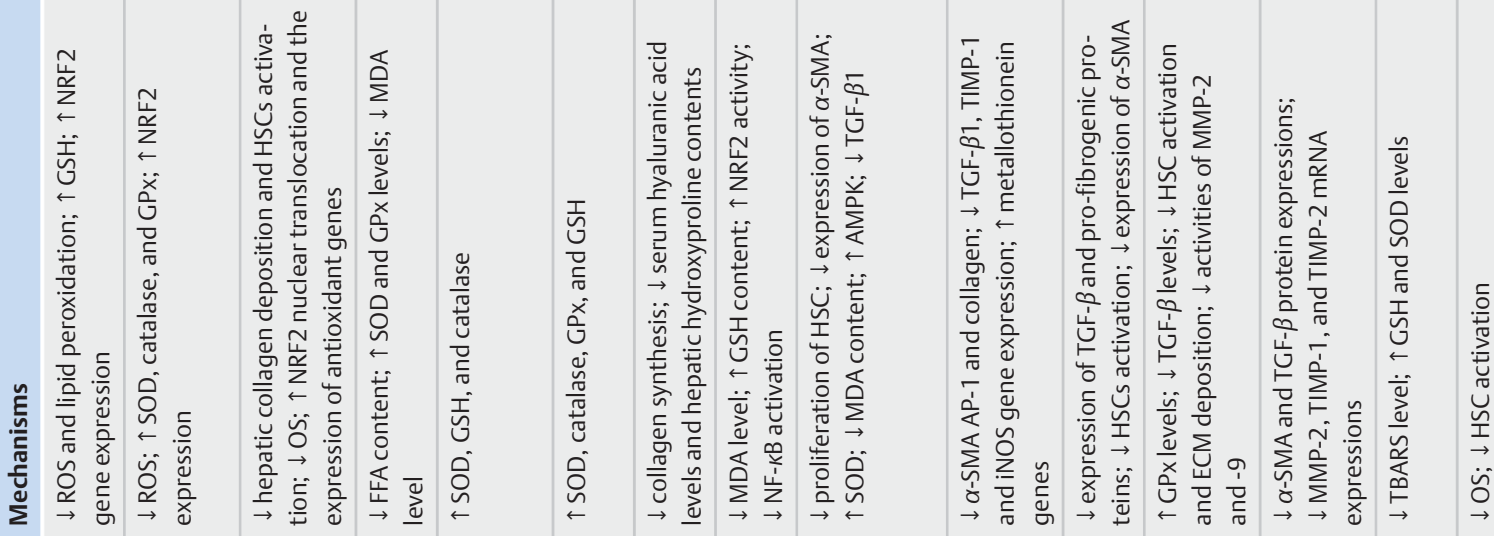

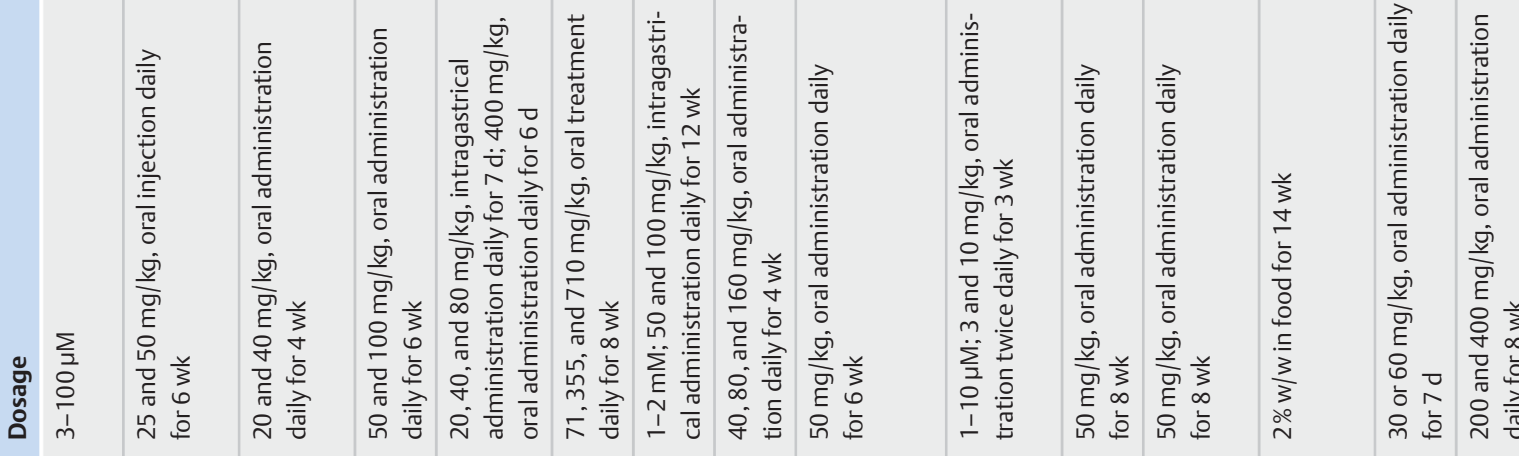

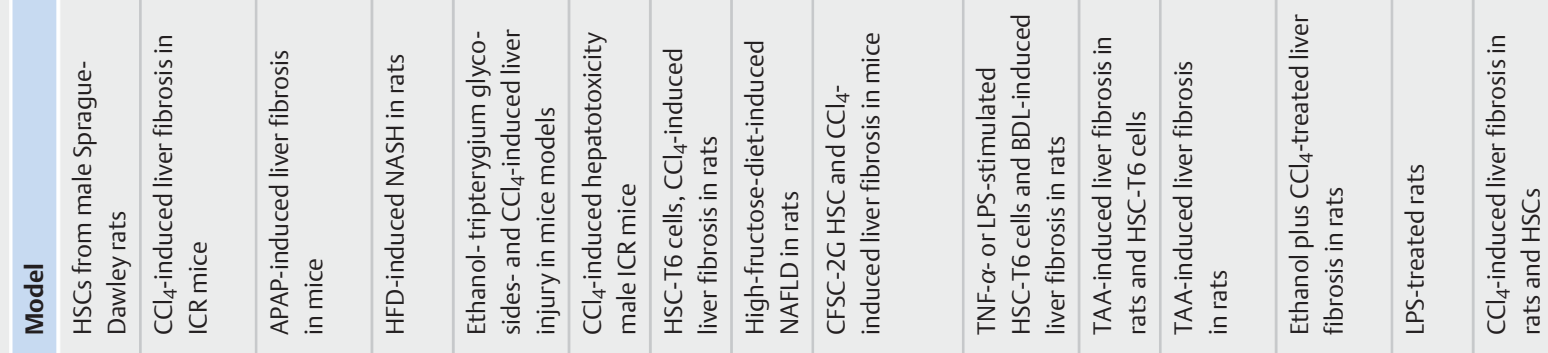

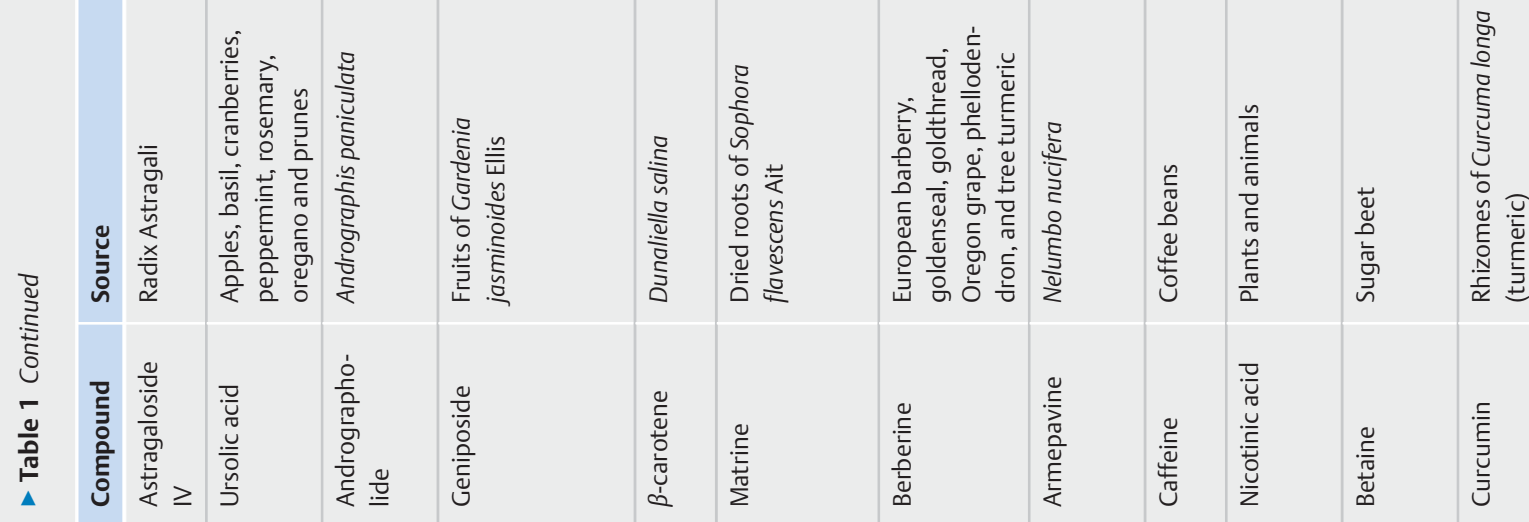




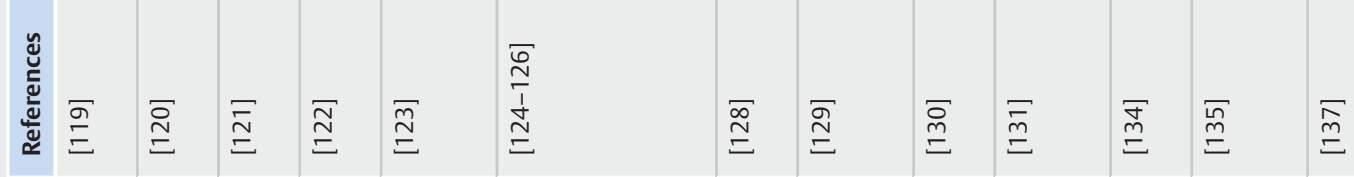

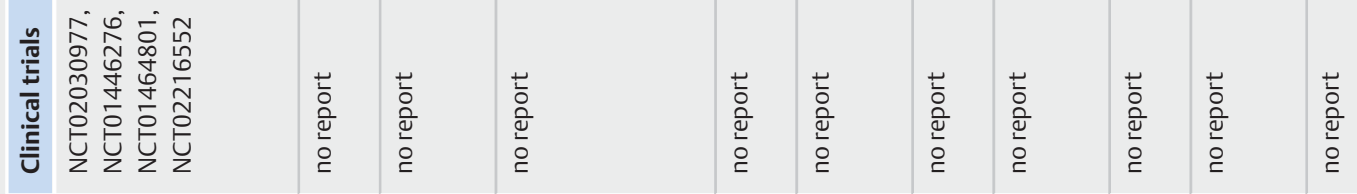

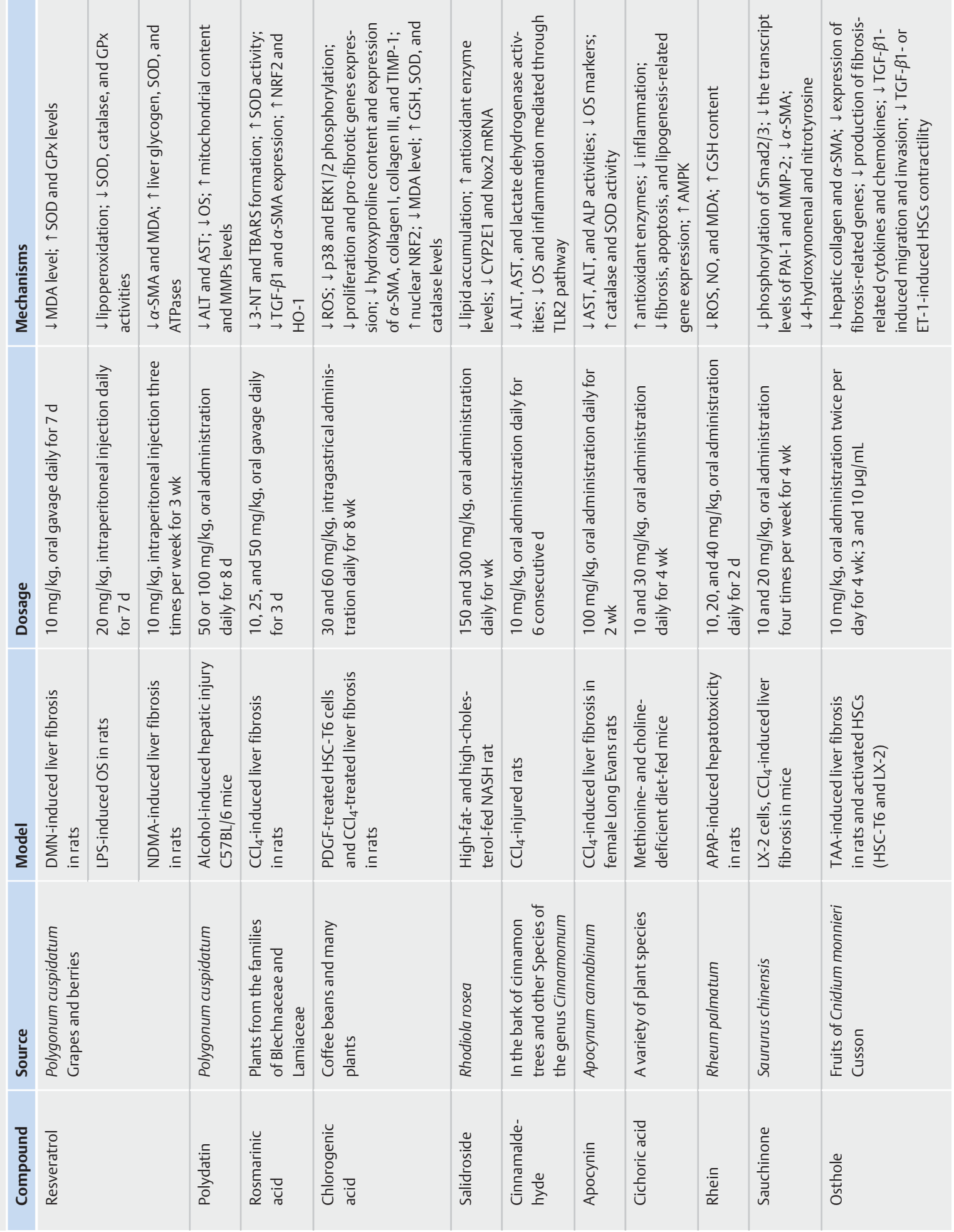


property. Some flavonoids have been reported with protective effect against liver fibrosis ( $\bullet$ Fig. 4 and Table 1).

Wogonin is a major flavonoid from the dried roots of Scutellaria baicalensis Georgi (Lamiaceae) [40]. Wogonin possesses the hepatic protective abilities including anti-virus, anti-inflammation, apoptosis induction of HCC cells, and free radical scavenging [41-43]. The ethanol extract from a herbal combinatorial formula (SRE, 1.25 and $6.25 \mathrm{mg} / \mathrm{kg}$ body weight, oral administration daily for $3 \mathrm{wk}$ ), containing wogonin as a major ingredient, showed a protective effect against dimethylnitrosamine (DMN)-induced liver fibrosis in rats [44]. Furthermore, the anti-fibrotic effect of SRE is mediated by elevating the levels of SOD, GPx, and catalase in DMN-exposed liver to prevent oxidative damage, decreasing the malondialdehyde (MDA) level to protect liver from DMN-induced lipid peroxidation, and ameliorating the oxidation of protein and DNA to restore liver injury and improve organ functions. SRE attenuates DMN-mediated liver injury by removing the excess accumulated ROS and inducing NRF2-ARE signaling to stimulate the expression of antioxidative enzymes [44].

Morin is a flavonoid isolated from Maclura pomifera (Raf.) C. K. Schneid. (Osage orange, Moraceae), Maclura tinctoria (L.) Steud. (old fustic, Moraceae), and the leaves of Psidium guajava L. (common guava, Myrtaceae). Morin inhibits the proliferation of human HSCs LX-2 cells, suppresses Wnt signaling, and induces G1 cell cycle arrest at the concentration of $50 \mu \mathrm{M}$. Morin $(50 \mathrm{mg} / \mathrm{kg}$ body weight, orally by gavage thrice per week for $6 \mathrm{wk}$ ) ameliorates diethylnitrosamine (DEN)-induced liver fibrosis in rats by downregulating the expression levels of glycogen synthase kinase $3 \beta$ (GSK-3 $\beta), \beta$-catenin, and cyclin D1 [45]. The treatment of morin (30 mg/kg body weight, oral administration daily for $8 \mathrm{wk}$ ) attenuates the liver index and serum biomarkers of liver function that were enhanced by chronic $\mathrm{CCl}_{4}$ intoxication, with silymarin (100 mg/kg body weight) as a positive control. Furthermore, morin inhibits the elevated levels of MDA and nitric oxide (NO) and restores GSH to its normal level in hepatocytes. The increased hepatic hydroxyproline content is markedly decreased by the administration of morin [46]. Hence, morin could be employed as a promising preventive natural supplement for liver fibrosis.

Galangin is a flavonol, present in Alpinia officinarum Hance (lesser galangal, Zingiberaceae) and Helichrysum aureonitens Sch. Bip. (Compositae). In liver fibrotic rats induced by the subcutaneous injection of $\mathrm{CCl}_{4}$, galangin (40 and $80 \mathrm{mg} / \mathrm{kg}$ body weight, orally by gavage daily for $12 \mathrm{wk}$ ) reverses the $\mathrm{CCl}_{4}$-induced increase of hyaluronic acid, laminin, alanine aminotransferase (ALT), and aspartate aminotransferase (AST) and decrease of total protein and albumin in serum; colchicin $(0.2 \mathrm{mg} / \mathrm{kg}$ body weight) was used as a positive control [47]. Galangin markedly reduces hepatic MDA and hydroxyproline concentration and increases the activities of liver SOD and GPx compared with $\mathrm{CCl}_{4}$-treated rats. In addition, galangin significantly downregulates the expression levels of $\alpha$-smooth muscle actin ( $\alpha$-SMA) and TGF- $\beta 1$ [47]. Hence, galangin might inhibit the $\mathrm{CCl}_{4}$-induced liver fibrosis in rats, probably by removing oxygen free radicals, decreasing lipid peroxidation, and inhibiting HSCs activation and proliferation.

Isorhamnetin commonly exists in pungent yellow and red onions (Amaryllidaceae). Isorhamnetin (50 and $100 \mu \mathrm{M}$ ) inhibits the TGF- $\beta 1$-induced expression of $\alpha$-SMA, plasminogen activator

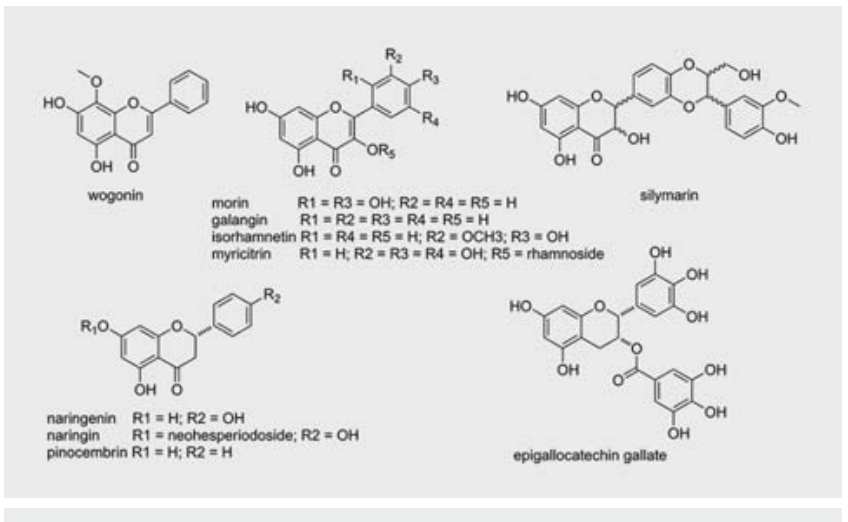

- Fig. 4 Flavonoids for the treatment of liver fibrosis.

inhibitor-1 (PAI-1), and collagen in primary murine HSCs and LX2 cells [48]. Isorhamnetin increases the nuclear translocation of NRF2 and blocks the TGF- $\beta 1$-induced ROS production in HSCs. Furthermore, isorhamnetin (10 and $30 \mathrm{mg} / \mathrm{kg}$ body weight, oral administration $5 \mathrm{~d} / \mathrm{wk}$ for $4 \mathrm{wk}$ ) prevents the $\mathrm{CCl}_{4}$-induced increase in serum ALT and AST levels and causes histopathological changes characterized by the decrease in collagen accumulation [48]. Isorhamnetin attenuates the $\mathrm{CCl}_{4}$-induced increase in the number of 4-hydroxynonenal and nitrotyrosine-positive cells and prevented GSH depletion. Isorhamnetin can inhibit the TGF- $\beta$ | Smad signaling pathway and relieve OS, thus inhibiting HSC activation and preventing liver fibrosis.

Myricitrin (myricetin-3-O- $\alpha$-rhamnoside) is a flavonoid from Myrica rubra Sieb. et Zucc. (Chinese bayberry, Myricaceae), possessing antioxidant and anti-inflammatory activities. Myricitrin (30 and $100 \mathrm{mg} / \mathrm{kg}$ body weight, orally by gavage daily for $2 \mathrm{~d}$ ) ameliorates the $\mathrm{CCl}_{4}$-induced increase in serum AST and ALT levels and the histopathological changes in the liver with silymarin (100 mg/kg body weight) as a positive control. Liver OS is reduced by myricitrin, as evidenced by the decrease in lipid peroxidation with a concomitant increase in GSH level and CYP2E1 expression. TGF- $\beta 1$ and $\alpha$-SMA expression is markedly ameliorated by myricitrin, indicating the inhibition of pro-fibrotic response. Myricitrin also improves the regeneration of hepatic tissue after $\mathrm{CCl}_{4}$-intoxication, as evidenced by increased proliferating cell nuclear antigen expression [49], indicating its significant anti-fibrotic activity.

Naringenin and its glycoside naringin are naturally occurring citrus flavanones predominantly found in grapes (Vitaceae), oranges (Rutaceae), and tomatoes (Solanaceae), possessing have a wide range of pharmacological properties, including anti-dyslipidemia, anti-obesity, and anti-fibrosis [50-52]. Naringin attenuates the nickel- or cadmium-induced liver toxicity in rats when orally administrated with $80 \mathrm{mg} / \mathrm{kg}$ body weight for $20 \mathrm{~d}$ or $50 \mathrm{mg} / \mathrm{kg}$ body weight for $4 \mathrm{wk}$, respectively, by significantly reducing lipid peroxidation and restoring the levels of antioxidant defense [53, 54]. Oral treatment of $50 \mathrm{mg} / \mathrm{kg}$ naringenin for $30 \mathrm{~d}$ decreases the expression of collagen in ethanol-induced liver fibrotic rats, which is associated with reduced OS and HSC activation $[55,56]$. In fructoseadministered rats, naringenin $(50 \mathrm{mg} / \mathrm{kg}$ body weight/day for $45 \mathrm{~d}$ ) reduces the levels of oxidative markers by inhibiting liver cell leakage, lipid peroxidation, and protein oxidation, and enhances 
the antioxidant potential by elevating enzymatic antioxidant activities including SOD, catalase, GPx, GST, and GR in liver. Moreover, naringenin supplementation increases the levels of non-enzymatic antioxidants such as GSH and vitamins $C$ and $E$ in rats [57]. Histopathological evidence indicates that naringenin $(50 \mathrm{mg} / \mathrm{kg}$ body weight, orally by gavage daily for $4 \mathrm{wk}$ ) reduces the liver damage in lead acetate-administered rats by improving GSH, catalase, and GPx levels. This finding demonstrates that naringenin serves as an antioxidant and chelating agent to compete against lead acetateinduced OS and damage in liver [58]. Hence, naringenin and naringin are potential antioxidants for treatment of liver fibrosis.

Pinocembrin is a flavonoid isolated from Penthorum chinense Pursh (Penthoraceae), which has been widely used for liver protection for thousands of years $[59,60]$. The water extract of $P$. chinense (5.15 and $10.30 \mathrm{~g} / \mathrm{kg}$ body weight/day for $4 \mathrm{wk}$ ) protects the liver against chronic ethanol-induced injury in mice by attenuating ROS generation and MDA level, restoring GSH depletion, and increasing SOD and GPx activities with silymarin $(86 \mathrm{mg} / \mathrm{kg}$ body weight) as a positive control [61]. In a recent study, pinocembrin from $P$. chinense suppresses the activation of both human HSC LX-2 and rat HSC-T6 cells at the concentrations of 10, 20, and $40 \mu \mathrm{M}$, mediating through ROS production alleviation, TGF- $\beta 1$ inhibition, and prevention of Smad nuclear translocation, which suggest its potential for protection against liver fibrosis [62]. Further in vivo studies are needed to verify the anti-fibrotic effect of $P$. chinense and pinocembrin.

Silymarin, a mixture of flavonolignans consisting of silibinin, isosilibinin, silicristin, and silidianin, is isolated from the seeds of Silybum marianum (L.) Gaertn. (milk thistle, Compositae) [63, 64]. Silymarin has been used for centuries to treat liver, spleen, and gallbladder disorders $[64,65]$. As the most well-studied natural product in the treatment of liver disease, silymarin has been recognized as "liver tonics" [66]. Silymarin is used to combat various liver conditions in both clinical settings and experimental models $[63,64,67,68]$. As an antioxidant, silymarin mainly reduces free radical production and lipid peroxidation [69]. Silymarin (100 mg/kg body weight, oral administration daily for $10 \mathrm{~d}$ ) significantly decreases the MDA level and increases the GSH level in $\mathrm{CCl}_{4}$-induced liver damage, indicating that this substance protects the liver from damage with notable redox functions [64]. Silymarin $(200 \mathrm{mg} / \mathrm{kg}$ body weight, oral administration 3 times daily for $8 \mathrm{wk}$ ) also improves liver fibrosis in $\mathrm{CCl}_{4}$-treated rats by decreasing the connective tissue growth factor [70]. Silymarin increases the activities of MnSOD, Cu/ZnSOD, and GPx in liver [70]. Silymarin (10 and $25 \mathrm{mg} / \mathrm{kg}$ body weight, oral administration daily for $12 \mathrm{wk}$ ) also prevents sodium nitrite-induced liver fibrosis in rats by reducing hepatic MDA levels, restoring the activity of hepatic GR and GPx, and inhibiting the deactivation of mitochondrial cytochrome $C$ oxidase function [71].

Several studies have revealed the protective effects of epigallocatechin gallate (EGCG) or green tea polyphenols against liver fibrosis on various animal models [72-74]. Intraperitoneal injection with $50 \mathrm{mg} / \mathrm{kg}$ of EGCG thrice per week for $8 \mathrm{wk}$ improves the hepatic histology (decreased number of fatty score, necrosis, and inflammatory foci), reduces liver injury, and attenuates hepatic changes, including fibrosis, by downregulating the expression levels of key pathological oxidative and pro-inflammatory

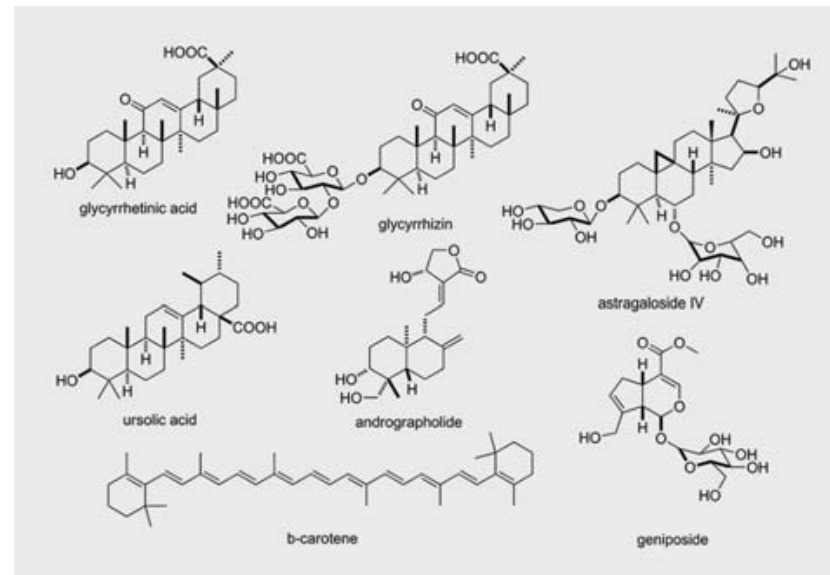

- Fig. 5 Terpenoids for the treatment of liver fibrosis.

markers in HFD-fed female Sprague-Dawley rats [75]. EGCG treatment also counteracts the activity of TGF/Smad and NF- $\kappa$ B pathways [75]. For the in vitro and in vivo models of thioacetamide (TAA)-induced hepatic fibrosis, EGCG inhibits the osteopontin (OPN)-dependent injury and fibrosis, primarily by upregulating miR-221 to accelerate OPN degradation [76]. Thus, green tea polyphenols and EGCG are useful supplements in the prevention of nonalcoholic fatty liver disease (NAFLD).

\section{Terpenoids}

Terpenoids are a large and diverse class of natural products derived from isoprene units. Some terpenoids have been reported with anti-fibrotic effects ( $\triangleright$ Fig. 5 and Table 1).

Glycyrrhetinic acid and glycyrrhizin are the major bioactive constituents isolated from the roots of Glycyrrhiza glabra L. (Leguminosae) [77]. In $\mathrm{CCl}_{4}$-treated mice, glycyrrhetinic acid (25, 50, and $100 \mathrm{mg} / \mathrm{kg}$ body weight, subcutaneous injection daily for $30 \mathrm{~d}$ ) reverses the $\mathrm{CCl}_{4}$-induced increase in serum monoamine oxidase and MDA and decrease in nuclear NRF2 expression and its target genes, including $\mathrm{Cu} / \mathrm{Zn}-\mathrm{SOD}$, catalase, and GPx, with silymarin (100 mg/kg body weight) as a positive control. In addition, glycyrrhetinic acid exhibits the antioxidant effects in vitro on $\mathrm{FeCl}_{2}$-ascorbate-induced lipid peroxidation in mouse liver homogenates and on 2,2-diphenyl-1-picrylhydrazyl-scavenging activity [78]. These results suggest that glycyrrhetinic acid may be an effective hepatoprotective agent and a viable candidate for treating liver fibrosis. Glycyrrhizin has various pharmacological effects and has been used to treat chronic hepatitis, especially hepatitis $C$ virus (HCV) infection and associated diseases [79]. Glycyrrhizin (12.5 and $25 \mathrm{mg} / \mathrm{kg}$ body weight, intraperitoneal injection daily for $8 \mathrm{wk}$ ) attenuates $\mathrm{CCl}_{4}$-induced liver fibrosis in rat by downregulating the expression of the specificity protein-1, the critical factor for the initiation of OS, in both transcriptional and translational levels [80]. In a fructose-induced metabolic syndrome rat model, a single intraperitoneal injection of $50 \mathrm{mg} / \mathrm{kg}$ body weight of glycyrrhizin prevents several complications of metabolic syndrome, including lipid peroxidation, protein carboxylation, and mitochondrial ROS generation, which resulted in attenuation of OS in liver by inhibiting the NF-kB inflammatory pathway and pre- 
venting the phosphorylation of MAPKs (mitogen-activated protein kinases) signaling pathway [81]. Glycyrrhetinic acid, glycyrrhizin, and the extract of $G$. glabra have shown protective effects against liver fibrosis in various in vitro and in vivo studies. Clinical trials are needed to further verify the anti-fibrotic effects.

Astragaloside IV, the active component of Radix Astragali (Leguminosae), possesses antioxidant property and anti-fibrotic potential for renal fibrosis, and 3-100 $\mathrm{\mu M}$ astragaloside IV attenuates OS in activated HSCs from male Sprague-Dawley rats by scavenging ROS, reducing lipid peroxidation, elevating the cellular level of GSH, and stimulating NRF2 gene expression. The depletion of cellular GSH by buthionine sulfoximine or abrogation of p38 MAPK with SB-203580 eliminated the inhibitory effects of astragaloside IV on genes relevant to HSC activation [82]. These studies provide novel insights into the mechanisms of astragaloside IV as an antifibrogenic candidate in the prevention and treatment of liver fibrosis.

Ursolic acid, a natural pentacyclic triterpenoid, has been found in various plants including apples (Rosaceae), basil (Lamiaceae), cranberries (Ericaceae), peppermint (Lamiaceae), rosemary (Lamiaceae), oregano (Lamiaceae), and prunes (Rosaceae) and possesses many biological activities, including antioxidation and anti-inflammation [83]. Ursolic acid (25 and $50 \mathrm{mg} / \mathrm{kg}$ body weight, oral injection daily for $6 \mathrm{wk}$ ) prevents $\mathrm{CCl}_{4}$-induced hepatotoxicity and fibrosis in ICR (Institute of Cancer Research) mice with colchicine (1 mg/kg body weight) as a positive control. The $\mathrm{CCl}_{4}$-induced profound elevations of OS, as well as inflammation and apoptosis in liver, are suppressed by ursolic acid through modulating the NRF2/ARE signaling pathway [84]. These results suggest that ursolic acid has hepatoprotective actions.

Andrographolide is a labdane-type diterpenoid isolated from Andrographis paniculata (Burm. f.) Wall. ex Nees (Acanthaceae), which has a broad range of therapeutic applications including anti-inflammatory and anti-platelet aggregation activities and potential antineoplastic properties [85]. Andrographolide (20 and $40 \mathrm{mg} / \mathrm{kg}$ body weight, oral administration daily for $4 \mathrm{wk}$ ) decreases hepatic collagen deposition and HSCs activation in APAP (acetaminophen)-induced mice [86]. Andrographolide alleviates liver OS and reduces ROS formation in HSCs. Andrographolide enhances the nuclear translocation of NRF2 and increases the expression of its downstream genes both in vitro and in vivo. Andrographolide might be clinically applied for the treatment of liver fibrosis.

Geniposide is an iridoid glycoside from the fruits of Gardenia jasminoides Ellis (Rubiaceae), which is useful against hyperlipidemia and fatty liver diseases [87,88]. Geniposide at 5 and $20 \mu \mathrm{M}$ effectively prevents TGF- $\beta 1$-induced fibrotic responses in AML12 cells [89]. In HFD-induced nonalcoholic steatohepatitis (NASH) rats, the free fatty acid content is reduced by geniposide ( 50 and $100 \mathrm{mg} / \mathrm{kg}$ body weight, oral administration daily for $6 \mathrm{wk}$ ), suggesting its potential to prevent HFD-induced liver injury [90]. Geniposide markedly increases endogenous antioxidants and SOD and GPx levels but decreases the MDA level to protect liver cells from oxidative damage [90]. The antioxidant property of geniposide is related to its ability to reduce free radical formation and enhance free radical scavenging. The hepatoprotective activities of geniposide $(20,40$, and $80 \mathrm{mg} / \mathrm{kg}$ body weight, intragastri-

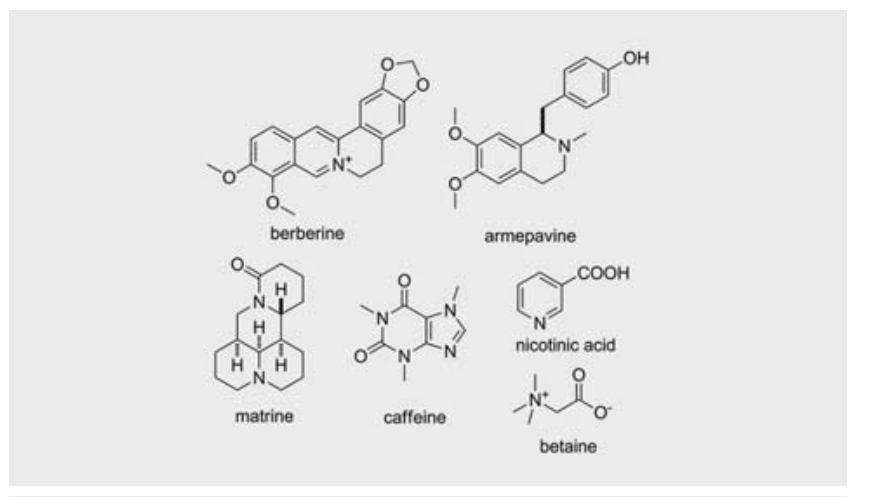

- Fig. 6 Alkaloids for the treatment of liver fibrosis.

cal administration daily for $7 \mathrm{~d}$ ) are also identified in mice models treated with alcohol, tripterygium glycosides, or $\mathrm{CCl}_{4}$ with bifendate $(150 \mathrm{mg} / \mathrm{kg}$ body weight) as a positive control $[91,92]$. The ALT, AST, and alkaline phosphatase (ALP) levels are significantly decreased by geniposide in the above models [91, 92]. Moreover, geniposide $(400 \mathrm{mg} / \mathrm{kg}$ body weight, oral administration daily for $6 \mathrm{~d})$ remarkably elevates the GSH level and increases the SOD and catalase activities in $\mathrm{CCl}_{4}$-induced liver damage mice with biphenyldicarboxylate pills (100 mg/kg body weight) as positive controls [93]. Thus, geniposide could be a potential candidate for the treatment of liver fibrosis.

Dunaliella salina (Dunal) Teodoresco (Dunaliellaceae) is a unicellular biflagellate green alga from the Chlorophyceae class, which is rich in $\beta$-carotene. In $\mathrm{CCl}_{4}$-induced hepatotoxicity male ICR mice, the oral treatment of $D$. salina extract $(71,355$, and $710 \mathrm{mg} / \mathrm{kg}$ body weight) daily for $8 \mathrm{wk}$ reverses the decreases in SOD, catalase, GPx, and GSH content and the increase in MDA content in liver. Liver histopathology shows that $\beta$-carotene reduces the incidence of liver lesions induced by $\mathrm{CCl}_{4}$ with silymarin $(200 \mathrm{mg} / \mathrm{kg})$ as a positive control [94]. The results suggest that $\beta$ carotene exhibits potential protective effects against $\mathrm{CCl}_{4}$-induced liver damage in mice.

\section{Alkaloids}

Alkaloids with protective effects against liver fibrosis were listed in - Fig. 6 and Table 1. Matrine is a primary active alkaloid isolated from the dried roots of Sophora flavescens Ait (Leguminosae), a commonly used traditional herb to cure hemafecia, dysentery, jaundice, and anuresis $[88,95]$. Matrine has a variety of pharmacological properties, including anti-inflammatory, immunity regulatory, antiviral, and anti-fibrotic effects [96-99]. Matrine (1$2 \mathrm{mM}$ ) markedly reduces serum- or TGF- $\beta 1$-driven collagen synthesis in HSC-T6 cells; matrine (50 and $100 \mathrm{mg} / \mathrm{kg}$ body weight, intragastrical administration daily for $12 \mathrm{wk}$ ) significantly decreases serum hyaluronic acid levels and hepatic hydroxyproline contents to attenuate $\mathrm{CCl}_{4}$-induced liver fibrosis [100]. In a highfructose-diet-induced NAFLD rat model, matrine $(40,80$, and $160 \mathrm{mg} / \mathrm{kg}$ body weight, oral administration daily for $4 \mathrm{wk}$ ) retards the histopathological progression by restoring the increased MDA level, depleting GSH content, facilitating NRF2 translocation to the nuclei, and inhibiting hepatic NF- $\kappa$ B activation [101]. 


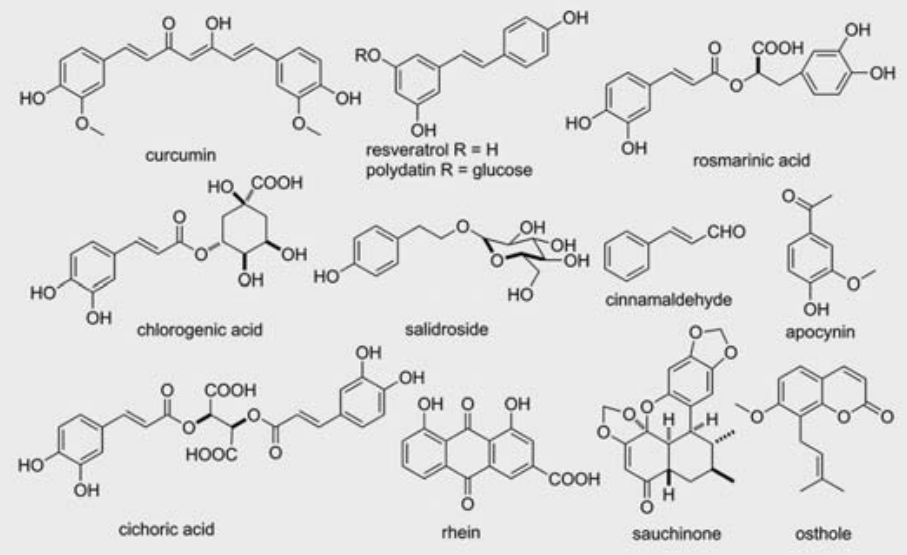

Fig. 7 Other natural compounds for the treatment of liver fibrosis.

Berberine is an alkaloid found in several plants including European barberry (Berberidaceae), goldenseal (Ranunculaceae), goldthread (Ranunculaceae), Oregon grape (Berberidaceae), phellodendron (Rutaceae), and tree turmeric (Berberidaceae). Oral administration of $50 \mathrm{mg} / \mathrm{kg}$ berberine daily for $6 \mathrm{wk}$ ameliorates $\mathrm{CCl}_{4}$-induced liver fibrosis in mice by decreasing the enzyme release of ALT, AST, and ALP in the serum and elevating SOD and reducing MDA content in the liver tissue. Moreover, berberine treatment activates AMP-activated protein kinase (AMPK), decreases the expression levels of TGF- $\beta 1$ and $\alpha$-SMA, and inhibits the proliferation of CFSC-2G HSCs [102]. These results may benefit the development of berberine in the prevention of chronic liver disease.

Armepavine is an active compound from Nelumbo nucifera Gaertn. (Nelumbonaceae), exerting anti-inflammatory effects on human peripheral blood mononuclear cells [103] and immunosuppressive effects on T lymphocytes and lupus nephritic mice [104]. In HSC-T6 cells, armepavine (1-10 $\mu \mathrm{M})$ attenuates TNF- $\alpha$ - and LPSstimulated $\alpha$-SMA protein expression and AP-1 activation. Armepavine ( 3 and $10 \mathrm{mg} / \mathrm{kg}$ body weight, oral administration twice daily for 3 wk) suppresses the TNF- $\alpha$-induced collagen deposition. In bile-duct-ligated-treated rats, armepavine treatment reduces the plasma AST and ALT levels, hepatic $\alpha$-SMA expression and collagen contents, and fibrosis scores. Moreover, armepavine attenuates the mRNA expression levels of TGF- $\beta 1$, TIMP- 1 , and inducible NO synthase but upregulates metallothionein gene expression [105]. Hence, armepavine has anti-fibrotic effects.

The support on the beneficial effects of caffeine on the liver is increasing. Caffeine $(50 \mathrm{mg} / \mathrm{kg}$ body weight, oral administration daily for $8 \mathrm{wk}$ ) protects against TAA-induced liver cirrhosis in rats by restoring the redox equilibrium and inhibiting the expression levels of TGF- $\beta$ and pro-fibrogenic proteins. Caffeine also inhibits HSCs activation and suppresses the expression of $\alpha$-SMA [106]. Caffeine may attenuate liver fibrotic processes.

Chronic TAA administration induces liver fibrosis, which is prevented by nicotinic acid. The oral administration of $50 \mathrm{mg} / \mathrm{kg}$ body weight nicotinic acid daily for 8 wk prevents the elevation of liver enzymes and restored the GPx levels. Additionally, nicotinic acid decreases the TGF- $\beta$ levels and attenuates the oxidative processes, reducing the HSC activation and ECM deposition.
Nicotinic acid decreases MMP-2 and - 9 activities [107]. Hence, nicotinic acid can be an anti-fibrotic agent against liver injury.

Betaine is an amino acid firstly discovered in sugar beet (Beta vulgaris L., Amaranthaceae), together with other beet cultivars. In ethanol with $\mathrm{CCl}_{4}$-treated liver fibrosis rats, betaine treatment ( $2 \%$ $\mathrm{w} / \mathrm{w}$ in food for $14 \mathrm{wk}$ ) diminishes the triglyceride level, the $\alpha$-SMA and TGF- $\beta$ protein levels, and MMP-2, TIMP-1, and TIMP-2 mRNA levels. Hence, the anti-fibrotic effect of betaine may be related to its suppressive effects on oxidant and inflammatory processes together with the HSC activation in alcoholic liver fibrosis [108].

\section{Other compounds}

In addition to the above-mentioned compounds, several other compounds have been reported to protect against liver fibrosis

\section{( $\vee$ Fig. 7 and Table 1).}

Curcumin is a polyphenolic compound isolated from the rhizomes of Curcuma longa L. (turmeric, Zingiberaceae) [109]. Curcumin can treat a wide variety of inflammatory diseases including cancer, diabetes, and fibrosis $[109,110]$. Curcumin has excellent antioxidant properties [111]. In LPS-challenged rats, the oral administration of 30 or $60 \mathrm{mg} / \mathrm{kg}$ curcumin daily for $7 \mathrm{~d}$ decreases the thiobarbituric acid reactive substances (TBARS) level and elevates GSH and SOD levels [112]. Curcumin (200 and $400 \mathrm{mg} / \mathrm{kg}$ body weight, oral administration daily for $8 \mathrm{wk}$ ) also protects the liver from $\mathrm{CCl}_{4}$-induced injury by attenuating $\mathrm{OS}$ in vivo and inhibits HSC activation in vitro [113].

Resveratrol is a polyphenolic compound isolated from Polygonum cuspidatum Sieb. et Zucc (Polygonaceae). As a natural phytoalexin, resveratrol is also present in various plant species including grapes and berries and acts against environmental stress and fungal infection [114]. Resveratrol possesses anti-aging, anti-carcinogenic, anti-inflammatory, and antioxidant properties [115118]. In the rat model, the oral gavage of $10 \mathrm{mg} / \mathrm{kg}$ resveratrol daily for $7 \mathrm{~d}$ protects $\mathrm{DMN}$-induced liver fibrosis by decreasing the MDA and increasing the SOD and GPx levels in liver [119]. Resveratrol $(20 \mathrm{mg} / \mathrm{kg}$ body weight, intraperitoneal injection daily for $7 \mathrm{~d})$ has a protective effect against LPS-induced OS in rat liver by reversing the LPS-induced lipoperoxidation and offsetting the depletion of SOD, catalase, and GPx activities [120]. In N'-nitrosodi- 
methylamine-induced liver fibrosis rats, resveratrol supplement $(10 \mathrm{mg} / \mathrm{kg}$ body weight, intraperitoneal injection 3 times per week for $3 \mathrm{wk}$ ) refurbishes the liver architecture by significantly restoring the levels of biomarkers of oxidative damage (MDA, SOD, protein carbonyls, and membrane-bound ATPases) and inhibits the $\alpha$-SMA expression and HSC activation to obstruct liver fibrosis [121].

Polydatin is a resveratrol glucoside isolated from $P$. cuspidatum. The oral administration of 50 or $100 \mathrm{mg} / \mathrm{kg}$ polydatin daily for $8 \mathrm{~d}$ alleviates the alcohol-induced hepatic injury by reducing the liver injury markers, ALT and AST, attenuating OS, and restoring the antioxidant balance in the hepatic tissue. Polydatin pre-treatment prevents alcohol-induced mitochondrial damage and refurbishes the MMP levels in the liver [122]. Hence, polydatin may have a potential benefit in preventing alcohol-induced acute hepatic injury.

Rosmarinic acid is a natural phenolic acid found in a variety of plants, especially the families of Blechnaceae and Lamiaceae. Rosmarinic acid $(10,25$, and $50 \mathrm{mg} / \mathrm{kg}$ body weight, oral gavage daily for $3 \mathrm{~d}$ ) decreases 3-nitrotyrosine and TBARS formation but increases SOD activity to ameliorate $O S$ in the liver tissue from $\mathrm{CCl}_{4}$-treated rats. Additionally, rosmarinic acid downregulates the expression levels of TGF- $\beta 1$ and $\alpha$-SMA, suggesting the suppression of pro-fibrotic response. The hepatoprotective activity of rosmarinic acid occurs with enhanced NRF2 and HO-1 expression [123]. Thus, rosmarinic acid possesses anti-fibrotic activity against acute liver toxicity.

Chlorogenic acid is a phenolic compound and exerts anti-inflammatory and antioxidant activities. Chlorogenic acid (30 and $60 \mathrm{mg} / \mathrm{kg}$ body weight, intragastrical administration daily for $8 \mathrm{wk}$ ) prevents $\mathrm{CCl}_{4}$-induced liver fibrosis by attenuating the inflammation and OS in rats [124-126]. Liver fibrosis is induced in $\mathrm{CCl}_{4}$-injected rats, characterized by increased hydroxyproline content and the expression of $\alpha$-SMA, collagen I, collagen III, and TIMP-1, which are alleviated markedly by chlorogenic acid [124]. Furthermore, chlorogenic acid increases the expression of nuclear NRF2 and its related antioxidant genes and suppresses the expression of NLRP3 inflammasome [127]. Chlorogenic acid decreases the MDA level and increases GSH, SOD, and catalase levels in liver tissues. In HSC-T6 cells, platelet-derived growth factor induces ROS production, p38 and ERK1/2 phosphorylation, proliferation and pro-fibrotic genes expression, which were reversed by chlorogenic acid treatment $(12.5,25$, and $50 \mu \mathrm{g} / \mathrm{mL})$ [126]. Hence, chlorogenic acid protects against liver fibrosis by suppressing OS.

Salidroside is a glucoside of tyrosol found from Rhodiola rosea L. (Crassulaceae). In high-fat and high-cholesterol-fed NASH rat model, salidroside treatment (150 and $300 \mathrm{mg} / \mathrm{kg}$ body weight, oral administration daily for weeks) effectively reduces lipid accumulation and inhibits liver injury in a dose-dependent manner [128]. Salidroside treatment restores the antioxidant enzyme levels and inhibits the expression of CYP2E1 and Nox2 mRNA in the liver, which prevents the initial step of free radical generation from NASH.

Cinnamaldehyde is a polyphenol possessing anti-inflammatory and antioxidant properties. In $\mathrm{CCl}_{4}$-induced liver injury rats, daily oral administration of $10 \mathrm{mg} / \mathrm{kg}$ cinnamaldehyde for 6 consecutive days significantly reverses the $\mathrm{CCl}_{4}$-induced elevation in serum ALT, AST, and lactate dehydrogenase activities [129]. Fur- thermore, cinnamaldehyde significantly reduces $\mathrm{CCl}_{4}$-induced OS and inflammation mediating through toll-like receptor-4 (TLR-4) signaling pathway, as well as the expression of downstream transcription factors such as NF- $\kappa$ B. The protective effect of cinnamaldehyde is comparable to that of the positive control silymarin (100 mg/kg body weight, oral administration). Hence, cinnamaldehyde is a promising candidate for hepatoprotective therapy.

Apocynin, also known as acetovanillone, is a natural organic compound structurally related to vanillin. Female Long Evans rats were administered with $\mathrm{CCl}_{4}$ orally $(1 \mathrm{~mL} / \mathrm{kg})$ twice a week for $2 \mathrm{wk}$ and were treated with apocynin ( $100 \mathrm{mg} / \mathrm{kg}$, orally) daily for 2 wk. Apocynin significantly reduces serum AST, ALT, and ALP activities and inhibits OS markers (MDA and NO levels) in $\mathrm{CCl}_{4}$ treated rats [130]. Apocynin treatment also restores the catalase and $\mathrm{SOD}$ activity in $\mathrm{CCl}_{4}$ treated rats. Hence, apocynin protects liver damage induced by $\mathrm{CCl}_{4}$ by inhibiting lipid peroxidation and stimulating the cellular antioxidant system.

Cichoric acid is a hydroxycinnamic acid, an organic compound of the phenylpropanoid class, which occurs in a variety of plant species. The oral administration of chicoric acid (10 and $30 \mathrm{mg} /$ $\mathrm{kg}$ ) daily for $4 \mathrm{wk}$ reduces the OS by upregulating antioxidant enzymes and decreases the inflammation by inhibiting pro-inflammatory cytokines and NF- $\kappa$ B activation in mice fed with a methionine- and choline-deficient diet [131]. In addition, chicoric acid reduces the fibrosis, apoptosis, and lipogenesis-related gene expression and increases the AMPK activation. Chicoric acid may be effective in the treatment of NAFLD and NASH.

Rhein is a lipophilic anthraquinone derivative found in Rheum palmatum L. (Polygonaceae), which has been used as traditional herbal medicine in China for thousands of years [132,133]. Rhein has various pharmacological effects including anti-inflammatory, antioxidant, and antimicrobial activities $[132,133]$. The potential protective effects of rhein were investigated on APAP-induced hepatotoxicity in rats [134]. The results show a reduction in ROS production, NO level, and MDA level and the restoration of GSH content by oral rhein administration $(10,20$, and $40 \mathrm{mg} / \mathrm{kg}$ body weigh daily for $2 \mathrm{~d}$ ) in APAP-induced liver injured rat [134]. The anti-fibrotic effect of rhein might be connected to its property in ameliorating OS.

Sauchinone is a lignan found in Saururus chinensis (Lour.) Baill. (Saururaceae). Sauchinone (10 and $30 \mu \mathrm{M}$ ) blocks the TGF- $\beta 1$-induced phosphorylation of Smad2/3 as well as the transcript levels of PAI- 1 and MMP-2 in LX-2 cells. Sauchinone $(10$ and $20 \mathrm{mg} / \mathrm{kg}$ body weight, oral administration 4 times per week for $4 \mathrm{wk}$ ) significantly inhibits liver fibrosis in CCl4-injured mice, as indicated by the decrease in the regions of hepatic degeneration, inflammatory cell infiltration and the intensity of $\alpha$-SMA staining in mice. Furthermore, sauchinone inhibits OS, as assessed by the staining of 4-hydroxynonenal and nitrotyrosine [135]. Sauchinone attenuates liver fibrosis and HSCs activation, which might be mediated by suppressing OS.

Osthole is an active component present in many medicinal plants especially in the fruits of Cnidium monnieri L. Cusson (Apiaceae), which has been clinically applied due to its various pharmacological properties, such as antioxidation and anti-inflammation [136]. In TAA-treated Sprague-Dawley rats, the oral administration of $10 \mathrm{mg} / \mathrm{kg}$ osthole twice per day for $4 \mathrm{wk}$ significantly re- 
duced liver injury by diminishing the plasma AST and ALT levels, improving the histological architecture, decreasing the collagen and $\alpha$-SMA accumulation, and improving hepatic fibrosis scores. In HSCs (HSC-T6 and LX-2), osthole (3 and $10 \mu \mathrm{g} / \mathrm{mL}$ ) reduces the expression of fibrosis-related genes, suppresses the production of fibrosis-related cytokines and chemokines, attenuates the TGF$\beta 1$-induced migration and invasion in HSCs, and alleviates the TGF- $\beta 1$ - or endothelin-1-induced HSCs contractility [137].

\section{Clinical Trials}

With the growing demands for a safe, effective, and economic treatment of liver fibrosis, an increasing number of researchers focused their studies in the research and development of agents against liver fibrosis in recent years. By searching the database of clinical registration in the United States (https://ClinicalTrials.gov/ ) by using "liver fibrosis" as the keyword, several natural compounds have been involved in clinical trials, including silymarin, glycyrrhizin, curcumin, and resveratrol. The single- and multipledose pharmacokinetics of silymarin were examined in patients with NAFLD or HCV to determine whether the disposition of silymarin and therefore its potential efficacy vary among liver disease populations. The efficacy of silymarin may be more readily observed in NAFLD patients because of their higher flavonolignan plasma concentrations and more extensive enterohepatic cycling compared with those in HCV patients [138]. A randomized, double-blind, placebo-controlled trial (NCT02006498) was performed on consecutive adults with biopsy-proven NASH and a NAFLD activity score (NAS) of 4 or more to verify the efficacy of silymarin in treating NASH. Patients were randomly assigned to groups given silymarin (700 mg) or placebo 3 times daily. After 48 wk, a significantly higher proportion of patients in the silymarin group had reductions in fibrosis based on histology and liver stiffness measurements. The silymarin group also had significant reductions in mean AST-to-platelet ratio index, fibrosis-4 score, and NAFLD fibrosis score [139]. Additionally, silymarin has been involved in a phase II clinical trial for noncirrhotic patients with nonalcoholic steatohepatitis (NCT00680407). Taken together, silymarin has been validated as a potential anti-fibrotic agent, but a larger trial is needed to confirm the clinical application of silymarin to reduce liver fibrosis.

A clinical trial was carried out to determine the addition of glycyrrhizin to entecavir in the treatment of chronic HBV (hepatitis B virus) and advanced fibrosis or cirrhosis (NCT03349008), which has not reported its results.

A clinical trial was performed to evaluate the effects of curcumin supplement on the metabolic factors and hepatic fibrosis in NAFLD patients with type 2 diabetes (NCT02908152); however, the results were not reported.

In a randomized, double-blinded, controlled clinical trial (NCT02030977), 50 NAFLD patients were supplemented with either a 500-mg resveratrol capsule or a placebo capsule for $12 \mathrm{wk}$. Both groups were advised to follow an energy-balanced diet and received physical activity recommendations. In both groups, anthropometric measurements (weight, body mass index, and waist circumference), liver enzymes, and steatosis grade were improved $(p<005)$. Resveratrol supplementation was associated with a significant reduction in liver enzyme ALT, inflammatory cytokines, NF- $\mathrm{BB}$ activity, serum cytokeratin-18, and hepatic steatosis grade, as compared with placebo supplementation. For the treatment of NAFLD, 12 wk of supplementation of $500 \mathrm{mg}$ resveratrol, along with lifestyle modification, is superior to lifestyle modification alone [140]. In another clinical trial (NCT01446276), a long-term (6 mo) and high-dose $(500 \mathrm{mg}$ 3 times daily) resveratrol treatment did not improve either basal or insulin-mediated VLDL-TG (very-low-density lipoprotein-triglycerides) secretion, oxidation, or clearance rates, nor did it affect palmitate or glucose turnover in nondiabetic, upper-body obese men with NAFLD. Likewise, no changes in body composition or liver fat content occurred following resveratrol compared with placebo treatment [141]. Therefore, more studies are needed to confirm the clinical application of resveratrol in treatment of liver fibrosis.

A Chinese herbal formula Fuzheng Huayu (NCT00854087) has completed the phase II clinical trial. In China, 2 products derived from traditional Chinese herbal medicine Fufang Biejia Ruangan Tablet (NCT01965418) and Fuzheng Huayu Tablet combined with Huangqi Decoction Granule (NCT00540397) have been involved in clinical trials. These agents target the treatment of liver fibrosis, NASH, HCV/HBV infections, NAFLD, or cholestasis. Some natural compounds and herbal medicine formula have been authenticated as anti-fibrotic agents in clinical trials, but further studies should be performed with a large trial.

\section{Conclusion and Perspective}

The authors retraced the panorama of liver fibrosis and the role of OS in the development of liver fibrosis. OS, a critical factor that mediates inflammatory response and triggers HSC activation, is a potential therapy target for treating fibrotic liver diseases. Naturally occurring antioxidants have been verified as potential therapeutic agents to balance the intracellular redox state. Plenty of evidence, both basic and clinical, provides a bright perspective on the antioxidative strategy for the treatment and prevention of liver fibrosis.

However, the clinical application of antioxidants in treatment of liver fibrosis is still far away.

1. Redox balance plays a key role in many physiological and pathological processes, and the liver is a central organ for metabolism. Thus, the determination of dosage, period, and route of administration of antioxidants in treating liver fibrosis involves a challenging translational research.

2. Most of the compounds possess a variety of pharmacological activities, indicating that the mechanisms for the treatment of liver fibrosis by antioxidants might partly be attributed to the antioxidative ability. Other mechanisms should also be considered. Natural compounds are supplied in high dosage in cell and animal experiments, and most compounds did not show a dose-effect manner for treating liver fibrosis, resulting in low possibility for clinical application.

3. Most of the reviewed antioxidants have limited oral bioavailability due to their hydrophobicity, quick degradation in the gastrointestinal tract, poor permeation through the intestinal membrane, extensive metabolism in the gut, and transport 
mediated by efflux pumps [142]. It might yield failed results on clinical trials. Several strategies could be employed to improve the poor oral bioavailability [142]. Micro and nanonization can improve the aqueous solubility and intestinal absorption. The encapsulation of lipophilic compounds into cyclodextrins can enhance the aqueous solubility and stability. Chitosan-based delivery systems can afford gastric stability, enhanced penetration through the intestinal membrane, and protection against intestinal metabolism. The co-administration of metabolic enzyme and P-glycoprotein inhibitors may enhance oral bioavailability. Despite the significant anti-fibrotic effect of naturally occurring antioxidants in animal models, these limitations render them ineffective in humans. More translational studies are needed to evaluate the effective and safe dose, the duration of treatment, and formulation strategy to realize the clinical application of antioxidants in treating liver fibrosis.

\section{Acknowledgements}

This work was supported by the Research Fund of University of Macau (MYRG2017-00109-ICMS and MYRG2018-00037-ICMS) and Science and Technology Development Fund, Macao S. A.R (FDCT 102/2017/A).

Conflict of Interest

The authors declare no conflict of interest.

\section{References}

[1] Thrift AP, El-Serag HB, Kanwal F. Global epidemiology and burden of HCV infection and HCV-related disease. Nat Rev Gastroenterol Hepatol 2017; 14: $122-132$

[2] Rinella ME. Nonalcoholic fatty liver disease: a systematic review. J Am Med Assoc 2015; 313: 2263-2273

[3] Scaglione S, Kliethermes S, Cao G, Shoham D, Durazo R, Luke A, Volk ML. The epidemiology of cirrhosis in the United States: a population-based study. J Clin Gastroenterol 2015; 49: 690-696

[4] Caballeria L, Pera G, Arteaga I, Rodriguez L, Aluma A, Morillas RM, de la Ossa N, Diaz A, Exposito C, Miranda D, Sanchez C, Prats RMA, Urquizu M, Salgado A, Alemany M, Martinez A, Majeed I, Fabrellas N, Graupera I, Planas R, Ojanguren I, Serra M, Toran P, Caballeria J, Gines P. High prevalence of liver fibrosis among European adults with unknown liver disease: a population-based study. Clin Gastroenterol Hepatol 2018; 16: 1138-1145

[5] Singal AG, El-Serag HB. Hepatocellular carcinoma from epidemiology to prevention: translating knowledge into practice. Clin Gastroenterol Hepatol 2015; 13: 2140-2151

[6] Friedman SL. Liver fibrosis-from bench to bedside. J Hepatol 2003; 38 (Suppl. 1): S38-S53

[7] Hernandez-Gea V, Friedman SL. Pathogenesis of Liver Fibrosis. In: Abbas AK, Galli SJ, Howley PM, eds. Annual Review of Pathology: Mechanisms of Disease, vol. 6. Palo Alto: Annual Reviews; 2011: 425-456

[8] Lim YS, Kim WR. The global impact of hepatic fibrosis and end-stage liver disease. Clin Liver Dis 2008; 12: 733-746

[9] Ley B, Collard HR. Epidemiology of idiopathic pulmonary fibrosis. Clin Epidemiol 2013; 5: 483-492

[10] Yang C, Zeisberg M, Mosterman B, Sudhakar A, Yerramalla U, Holthaus K, Xu L, Eng F, Afdhal N, Kalluri R. Liver fibrosis: insights into migration of hepatic stellate cells in response to extracellular matrix and growth factors. Gastroenterology 2003; 124: 147-159
[11] Visse R, Nagase H. Matrix metalloproteinases and tissue inhibitors of metalloproteinases: structure, function, and biochemistry. Circ Res 2003; 92: 827-839

[12] Page-McCaw A, Ewald AJ, Werb Z. Matrix metalloproteinases and the regulation of tissue remodelling. Nat Rev Mol Cell Biol 2007; 8: 221-233

[13] Friedman SL. Evolving challenges in hepatic fibrosis. Nat Rev Gastroenterol Hepatol 2010; 7: 425-436

[14] Krizhanovsky V, Yon M, Dickins RA, Hearn S, Simon J, Miething C, Yee H, Zender L, Lowe SW. Senescence of activated stellate cells limits liver fibrosis. Cell 2008; 134: 657-667

[15] Jiang Y, Wang C, Li YY, Wang XC, An JD, Wang YJ, Wang XJ. Mistletoe alkaloid fractions alleviates carbon tetrachloride-induced liver fibrosis through inhibition of hepatic stellate cell activation via TGF-beta/Smad interference. J Ethnopharmacol 2014; 158: 230-238

[16] Liu M, Xu Y, Han X, Yin L, Xu L, Qi Y, Zhao Y, Liu K, Peng J. Dioscin alleviates alcoholic liver fibrosis by attenuating hepatic stellate cell activation via the TLR4/MyD88/NF-kappaB signaling pathway. Sci Rep 2015; 5 : 18038

[17] Zhou L, Dong X, Wang L, Shan L, Li T, Xu W, Ding Y, Lai M, Lin X, Dai M, Bai X, Jia C, Zheng $H$. Casticin attenuates liver fibrosis and hepatic stellate cell activation by blocking TGF-beta/Smad signaling pathway. Oncotarget 2017; 8: 56267-56280

[18] Li S, Tan HY, Wang N, Zhang Z], Lao L, Wong CW, Feng Y. The role of oxidative stress and antioxidants in liver diseases. Int J Mol Sci 2015; 16: 26087-26124

[19] Louvet A, Mathurin P. Alcoholic liver disease: mechanisms of injury and targeted treatment. Nat Rev Gastroenterol Hepatol 2015; 12: 231-242

[20] Kakimoto PA, Kowaltowski A]. Effects of high fat diets on rodent liver bioenergetics and oxidative imbalance. Redox Biol 2016; 8: 216-225

[21] Ivanov AV, Valuev-Elliston VT, Tyurina DA, Ivanova ON, Kochetkov SN, Bartosch B, Isaguliants MG. Oxidative stress, a trigger of hepatitis $C$ and $B$ virus-induced liver carcinogenesis. Oncotarget 2017; 8: 3895-3932

[22] Sutti S, Jindal A, Locatelli I, Vacchiano M, Gigliotti L, Bozzola C, Albano E. Adaptive immune responses triggered by oxidative stress contribute to hepatic inflammation in NASH. Hepatology 2014; 59: 886-897

[23] Malhotra JD, Miao H, Zhang K, Wolfson A, Pennathur S, Pipe SW, Kaufman RJ. Antioxidants reduce endoplasmic reticulum stress and improve protein secretion. Proc Natl Acad Sci U S A 2008; 105: 1852518530

[24] Murphy MP. How mitochondria produce reactive oxygen species. Biochem J 2009; 417: 1-13

[25] Ushio-Fukai M. Localizing NADPH oxidase-derived ROS. Sci STKE 2006; 349: re8

[26] Mathews S, Feng D, Maricic I, Ju C, Kumar V, Gao B. Invariant natural killer T cells contribute to chronic-plus-binge ethanol-mediated liver injury by promoting hepatic neutrophil infiltration. Cell Mol Immunol 2016; 13: 206-216

[27] Poli G. Pathogenesis of liver fibrosis: role of oxidative stress. Mole Aspects Med 2000; 21: 49-98

[28] Bataller R, Brenner DA. Liver fibrosis. J Clin Invest 2005; 115: 209-218

[29] Itagaki T, Shimizu I, Cheng X, Yuan Y, Oshio A, Tamaki K, Fukuno H, Honda $\mathrm{H}$, Okamura $\mathrm{Y}$, Ito $\mathrm{S}$. Opposing effects of oestradiol and progesterone on intracellular pathways and activation processes in the oxidative stress induced activation of cultured rat hepatic stellate cells. Gut 2005; 54: 1782-1789

[30] Sánchez-Valle V, Chavez-Tapia NC, Uribe M, Méndez-Sánchez N. Role of oxidative stress and molecular changes in liver fibrosis: a review. Curr Med Chem 2012; 19: 4850-4860

[31] Nishi T, Shimizu N, Hiramoto M, Sato I, Yamaguchi Y, Hasegawa M, Aizawa S, Tanaka H, Kataoka K, Watanabe H. Spatial redox regulation of a critical cysteine residue of NF-kB in vivo. J Biol Chem 2002; 277: 4454844556 
[32] Korn SH, Wouters EF, Vos N, Janssen-Heininger YM. Cytokine-induced activation of nuclear factor- $\kappa B$ is inhibited by hydrogen peroxide through oxidative inactivation of ІкB kinase. J Biol Chem 2001; 276: 35693-35700

[33] Kaspar JW, Niture SK, Jaiswal AK. Nrf2: INrf2 (Keap1) signaling in oxidative stress. Free Radic Biol Med 2009; 47: 1304-1309

[34] Salomone F, Godos J, Zelber-Sagi S. Natural antioxidants for non-alcoholic fatty liver disease: molecular targets and clinical perspectives. Liver Int 2016; 36: 5-20

[35] Parola M, Robino G. Oxidative stress-related molecules and liver fibrosis. J Hepatol 2001; 35: 297-306

[36] Singal AK, Jampana SC, Weinman SA. Antioxidants as therapeutic agents for liver disease. Liver Int 2011; 31: 1432-1448

[37] Richter K, Konzack A, Pihlajaniemi T, Heljasvaara R, Kietzmann T. Redoxfibrosis: impact of TGFbeta1 on ROS generators, mediators and functional consequences. Redox Biol 2015; 6: 344-352

[38] Richter K, Kietzmann T. Reactive oxygen species and fibrosis: further evidence of a significant liaison. Cell Tissue Res 2016; 365: 591-605

[39] Nanthakumar CB, Hatley RJ, Lemma S, Gauldie J, Marshall RP, Macdonald SJ. Dissecting fibrosis: therapeutic insights from the small-molecule toolbox. Nat Rev Drug Discov 2015; 14: 693-720

[40] Dong LL, Fu Y], Zu YG, Luo M, Wang W, Li CY, Mu PS. An enhanced preparation and purification of the major antioxidants baicalein and wogonin from Scutellariae radix. Food Chem 2012; 133: 430-436

[41] Lee H, Kim YO, Kim H, Kim SY, Noh HS, Kang SS, Cho G], Choi WS, Suk K. Flavonoid wogonin from medicinal herb is neuroprotective by inhibiting inflammatory activation of microglia. FASEB J 2003; 17: 1943-1944

[42] Khan NM, Haseeb A, Ansari MY, Devarapalli P, Haynie S, Haqqi TM. Wogonin, a plant derived small molecule, exerts potent anti-inflammatory and chondroprotective effects through the activation of ROS/ERK/ Nrf2 signaling pathways in human osteoarthritis chondrocytes. Free Radic Biol Med 2017; 106: 288-301

[43] Li-Weber M. New therapeutic aspects of flavones: the anticancer properties of Scutellaria and its main active constituents wogonin, baicalein and baicalin. Cancer Treat Rev 2009; 35: 57-68

[44] Pan TL, Wang PW, Huang CH, Leu YL, Wu TH, Wu YR, You JS. Herbal formula, Scutellariae radix and Rhei rhizoma attenuate dimethylnitrosamine-induced liver fibrosis in a rat model. Sci Rep 2015; 5: 11734

[45] MadanKumar P, NaveenKumar P, Manikandan S, Devaraj H, Niranjali Devaraj S. Morin ameliorates chemically induced liver fibrosis in vivo and inhibits stellate cell proliferation in vitro by suppressing Wnt/betacatenin signaling. Toxicol Appl Pharmacol 2014; 277: 210-220

[46] Heeba GH, Mahmoud ME. Therapeutic potential of morin against liver fibrosis in rats: modulation of oxidative stress, cytokine production and nuclear factor kappa B. Environ Toxicol Pharmacol 2014; 37: 662-671

[47] Wang X, Gong G, Yang W, Li Y, Jiang M, Li L. Antifibrotic activity of galangin, a novel function evaluated in animal liver fibrosis model. Environ Toxicol Pharmacol 2013; 36: 288-295

[48] Yang JH, Kim SC, Kim KM, Jang CH, Cho SS, Kim SJ, Ku SK, Cho IJ, Ki SH. Isorhamnetin attenuates liver fibrosis by inhibiting TGF-beta/Smad signaling and relieving oxidative stress. Eur J Pharmacol 2016; 783: 92-102

[49] Domitrovic R, Rashed K, Cvijanovic O, Vladimir-Knezevic S, Skoda M, Visnic A. Myricitrin exhibits antioxidant, anti-inflammatory and antifibrotic activity in carbon tetrachloride-intoxicated mice. Chem Biol Interact 2015; 230: 21-29

[50] Erlund I. Review of the flavonoids quercetin, hesperetin naringenin. dietary sources, bioactivities, and epidemiology. Nutr Res 2004; 24: 851874

[51] Wilcox LJ, Borradaile NM, Huff MW. Antiatherogenic properties of naringenin, a citrus flavonoid. Cardiovasc Drug Rev 1999; 17: 160-178

[52] Mir IA, Tiku AB. Chemopreventive and therapeutic potential of "naringenin", a flavanone present in citrus fruits. Nutr Cancer 2015; 67: 27-42
[53] Pari L, Amudha K. Hepatoprotective role of naringin on nickel-induced toxicity in male Wistar rats. Eur J Pharmacol 2011; 650: 364-370

[54] Renugadevi J, Prabu SM. Cadmium-induced hepatotoxicity in rats and the protective effect of naringenin. Exp Toxicol Pathol 2010; 62: 171181

[55] Jayachitra J, Nalini N. Effect of naringenin (citrus flavanone) on lipid profile in ethanol-induced toxicity in rats. J Food Biochem 2012; 36: 502511

[56] Jayaraman J, Namasivayam N. Naringenin modulates circulatory lipid peroxidation, anti-oxidant status and hepatic alcohol metabolizing enzymes in rats with ethanol induced liver injury. Fundam Clin Pharmacol 2011; 25: 682-689

[57] Kannappan S, Palanisamy N, Anuradha CV. Suppression of hepatic oxidative events and regulation of eNOS expression in the liver by naringenin in fructose-administered rats. Eur J Pharmacol 2010; 645: 177-184

[58] Ozkaya A, Sahin Z, Dag U, Ozkaraca M. Effects of naringenin on oxidative stress and histopathological changes in the liver of lead acetate administered rats. J Biochem Mol Toxicol 2016; 30: 243-248

[59] Wang A, Lin L, Wang Y. Traditional Chinese herbal medicine Penthorum chinense Pursh: a phytochemical and pharmacological review. Am J Chin Med 2015; 43: 601-620

[60] Wang A, Wang S, Jiang Y, Chen M, Wang Y, Lin L. Bio-assay guided identification of hepatoprotective polyphenols from Penthorum chinense Pursh on t-BHP induced oxidative stress injured L02 cells. Food Funct 2016; 7: 2074-2083

[61] Cao YW, jiang Y, Zhang DY, Wang M, Chen WS, Su H, Wang YT, Wan JB. Protective effects of Penthorum chinense Pursh against chronic ethanolinduced liver injury in mice. J Ethnopharmacol 2015; 161: 92-98

[62] Zhou F, Wang A, Li D, Wang Y, Lin L. Pinocembrin from Penthorum chinense Pursh suppresses hepatic stellate cells activation through a unified SIRT3-TGF-beta-Smad signaling pathway. Toxicol Appl Pharmacol 2018; 341: $38-50$

[63] Gazak R, Walterova D, Kren V. Silybin and silymarin-new and emerging applications in medicine. Curr Med Chem 2007; 14: 315-338

[64] Shaker E, Mahmoud H, Mnaa S. Silymarin, the antioxidant component and Silybum marianum extracts prevent liver damage. Food Chem Toxicol 2010; 48: 803-806

[65] Crocenzi FA, Roma MG. Silymarin as a new hepatoprotective agent in experimental cholestasis: new possibilities for an ancient medication. Curr Med Chem 2006; 13: 1055-1074

[66] Hackett ES, Twedt DC, Gustafson DL. Milk thistle and its derivative compounds: a review of opportunities for treatment of liver disease. J Vet Intern Med 2013; 27: 10-16

[67] Rastogi R, Srivastava AK, Rastogi AK. Long term effect of aflatoxin B(1) on lipid peroxidation in rat liver and kidney: effect of picroliv and silymarin. Phytother Res 2001; 15: 307-310

[68] Saller R, Meier R, Brignoli R. The use of silymarin in the treatment of liver diseases. Drugs 2001; 61: 2035-2063

[69] Abenavoli L, Milic N, Capasso F. Anti-oxidant therapy in non-alcoholic fatty liver disease: the role of silymarin. Endocrine 2012; 42: 754-755

[70] Tzeng JI, Chen MF, Chung HH, Cheng JT. Silymarin decreases connective tissue growth factor to improve liver fibrosis in rats treated with carbon tetrachloride. Phytother Res 2013; 27: 1023-1028

[71] Sherif IO, Al-Gayyar MM. Antioxidant, anti-inflammatory and hepatoprotective effects of silymarin on hepatic dysfunction induced by sodium nitrite. Eur Cytokine Netw 2013; 24: 114-121

[72] Zhen MC, Wang Q, Huang XH, Cao LQ, Chen XL, Sun K, Liu Y], Li W, Zhang LJ. Green tea polyphenol epigallocatechin-3-gallate inhibits oxidative damage and preventive effects on carbon tetrachloride-induced hepatic fibrosis. J Nutr Biochem 2007; 18: 795-805 
[73] Kim HK, Yang TH, Cho HY. Antifibrotic effects of green tea on in vitro and in vivo models of liver fibrosis. World J Gastroenterol 2009; 15: 5200 5205

[74] Tipoe GL, Leung TM, Liong EC, Lau TY, Fung ML, Nanji AA. Epigallocatechin-3-gallate (EGCG) reduces liver inflammation, oxidative stress and fibrosis in carbon tetrachloride (CCl4)-induced liver injury in mice. Toxicology 2010; 273: 45-52

[75] Xiao J, Ho CT, Liong EC, Nanji AA, Leung TM, Lau TY, Fung ML, Tipoe GL. Epigallocatechin gallate attenuates fibrosis, oxidative stress, and inflammation in non-alcoholic fatty liver disease rat model through TGF/SMAD, PI3 K/Akt/FoxO1, and NF-kappa B pathways. Eur ] Nutr 2014; 53: 187199

[76] Arffa ML, Zapf MA, Kothari AN, Chang V, Gupta GN, Ding X, Al-Gayyar MM, Syn W, Elsherbiny NM, Kuo PC, Mi Z. Epigallocatechin-3-gallate upregulates miR-221 to inhibit osteopontin-dependent hepatic fibrosis. PLoS One 2016; 11: e0167435

[77] Graebin CS, Verli H, Guimaraes JA. Glycyrrhizin and glycyrrhetic acid: scaffolds to promising new pharmacologically active compounds. J Brazil Chem Soc 2010; 21: 1595-1615

[78] Chen S, Zou L, Li L, Wu T. The protective effect of glycyrrhetinic acid on carbon tetrachloride-induced chronic liver fibrosis in mice via upregulation of Nrf2. PLoS One 2013; 8: e53662

[79] Cinatl ], Morgenstern B, Bauer G, Chandra P, Rabenau H, Doerr HW. Glycyrrhizin, an active component of liquorice roots, and replication of SARS-associated coronavirus. Lancet 2003; 361: 2045-2046

[80] Qu Y, Zong L, Xu M, Dong Y, Lu L. Effects of $18 \alpha$-glycyrrhizin on TGF- $\beta 1$ / Smad signaling pathway in rats with carbon tetrachloride-induced liver fibrosis. Int J Clin Exp Pathol 2015; 8: 1292-1301

[81] Sil R, Ray D, Chakraborti AS. Glycyrrhizin ameliorates metabolic syndrome-induced liver damage in experimental rat model. Mol Cell Biochem 2015; 409: 177-189

[82] Li X, Wang X, Han C, Wang X, Xing G, Zhou L, Li G, Niu Y. Astragaloside IV suppresses collagen production of activated hepatic stellate cells via oxidative stress-mediated p38 MAPK pathway. Free Radic Biol Med 2013; 60: 168-176

[83] Wu HY, Chang Cl, Lin BW, Yu FL, Lin PY, Hsu JL, Yen CH, Liao MH, Shih WL. Suppression of hepatitis B virus $x$ protein-mediated tumorigenic effects by ursolic acid. J Agric Food Chem 2011; 59: 1713-1722

[84] Ma JQ, Ding J, Zhang L, Liu CM. Protective effects of ursolic acid in an experimental model of liver fibrosis through Nrf2/ARE pathway. Clin Res Hepatol Gastroenterol 2015; 39: 188-197

[85] Dai Y, Chen SR, Chai L, Zhao J, Wang Y, Wang Y. Overview of pharmacological activities of Andrographis paniculata and its major compound andrographolide. Crit Rev Food Sci Nutr 2018. doi:10.1080/10408398. 2018.1501657

[86] Yan H, Huang Z, Bai Q, Sheng Y, Hao Z, Wang Z, Ji L. Natural product andrographolide alleviated APAP-induced liver fibrosis by activating Nrf2 antioxidant pathway. Toxicology 2018; 396-397: 1-12

[87] Shan M, Yu S, Yan H, Guo S, Xiao W, Wang Z, Zhang L, Ding A, Wu Q, Li SFY. A review on the phytochemistry, pharmacology, pharmacokinetics and toxicology of geniposide, a natural product. Molecules 2017; 22: E1689

[88] Zhang WL, Zhu L, Jiang JG. Active ingredients from natural botanicals in the treatment of obesity. Obes Rev 2014; 15: 957-967

[89] Park JH, Yoon J, Lee KY, Park B. Effects of geniposide on hepatocytes undergoing epithelial-mesenchymal transition in hepatic fibrosis by targeting TGFbeta/Smad and ERK-MAPK signaling pathways. Biochimie 2015; 113: 26-34

[90] Ma T, Huang C, Zong G, Zha D, Meng X, Li ], Tang W. Hepatoprotective effects of geniposide in a rat model of nonalcoholic steatohepatitis. J Pharm Pharmacol 2011; 63: 587-593
[91] Wang J, Miao M, Qu L, Cui Y, Zhang Y. Protective effects of geniposide against tripterygium glycosides (TG)-induced liver injury and its mechanisms. J Toxicol Sci 2016; 41: 165-173

[92] Wang J, Zhang Y, Liu R, Li X, Cui Y, Qu L. Geniposide protects against acute alcohol-induced liver injury in mice via up-regulating the expression of the main antioxidant enzymes. Can J Physiol Pharmacol 2015; 93: $261-267$

[93] Chen P, Chen Y, Wang Y, Cai S, Deng L, Liu ], Zhang H. Comparative evaluation of hepatoprotective activities of geniposide, crocins and crocetin by $\mathrm{CCl}_{4}$-induced liver injury in mice. Biomol Ther 2016; 24 : 156-162

[94] Hsu YW, Tsai CF, Chang WH, Ho YC, Chen WK, Lu FJ. Protective effects of Dunaliella salina - a carotenoids-rich alga, against carbon tetrachloride-induced hepatotoxicity in mice. Food Chem Toxicol 2008; 46: 3311-3317

[95] Qiu S, Sun H, Zhang AH, Xu HY, Yan GL, Han Y, Wang XJ. Natural alkaloids: basic aspects, biological roles, and future perspectives. Chin J Nat Med 2014; 12: 401-406

[96] Sun N, Sun P, Lv H, Sun Y, Guo J, Wang Z, Luo T, Wang S, Li H. Matrine displayed antiviral activity in porcine alveolar macrophages coinfected by porcine reproductive and respiratory syndrome virus and porcine circovirus type 2. Sci Rep 2016; 6: 24401

[97] Zhang YB, Zhan LQ, Li GQ, Wang F, Wang Y, Li YL, Ye WC, Wang GC. Dimeric matrine-type alkaloids from the roots of Sophora flavescens and their anti-hepatitis B virus activities. J Org Chem 2016; 81: 62736280

[98] Feng Y, Ying HY, Qu Y, Cai XB, Xu MY, Lu LG. Novel matrine derivative MD-1 attenuates hepatic fibrosis by inhibiting EGFR activation of hepatic stellate cells. Protein Cell 2016; 7: 662-672

[99] Zhang Y, Cui L, Guan GC, Wang JK, Qiu C, Yang TL, Guo Y, Liu ZW. Matrine suppresses cardiac fibrosis by inhibiting the TGF- $\beta /$ Smad pathway in experimental diabetic cardiomyopathy. Mol Med Rep 2018; 17 : 1775-1781

[100] Zhang JP, Zhang M, Zhou JP, Liu FT, Zhou B, Xie WF, Guo C. Antifibrotic effects of matrine on in vitro and in vivo models of liver fibrosis in rats. Acta Pharmacol Sin 2001; 22: 183-186

[101] Zhang HF, Shi LJ, Song GY, Cai ZG, Wang C, An RJ. Protective effects of matrine against progression of high-fructose diet-induced steatohepatitis by enhancing antioxidant and anti-inflammatory defences involving Nrf2 translocation. Food Chem Toxicol 2013; 55: 70-77

[102] Li J, Pan Y, Kan M, Xiao X, Wang Y, Guan F, Zhang X, Chen L. Hepatoprotective effects of berberine on liver fibrosis via activation of AMPactivated protein kinase. Life Sci 2014; 98: 24-30

[103] Liu CP, Kuo YC, Shen CC, Wu MH, Liao JF, Lin YL, Chen CF, Tsai W]. (S)-armepavine inhibits human peripheral blood mononuclear cell activation by regulating Itk and PLCgamma activation in a PI-3K-dependent manner. J Leukoc Biol 2007; 81: 1276-1286

[104] Liu CP, Tsai WJ, Shen CC, Lin YL, Liao JF, Chen CF, Kuo YC. Inhibition of (S)-armepavine from Nelumbo nucifera on autoimmune disease of MRL/MpJ-Ipr/lpr mice. Eur J Pharmacol 2006; 531: 270-279

[105] Weng TC, Shen CC, Chiu YT, Lin YL, Kuo CD, Huang YT. Inhibitory effects of armepavine against hepatic fibrosis in rats. J Biomed Sci 2009; 16: 78

[106] Arauz J, Zarco N, Segovia J, Shibayama M, Tsutsumi V, Muriel P. Caffeine prevents experimental liver fibrosis by blocking the expression of TGF-beta. Eur J Gastroenterol Hepatol 2014; 26: 164-173

[107] Arauz J, Rivera-Espinoza Y, Shibayama M, Favari L, Flores-Beltran RE, Muriel P. Nicotinic acid prevents experimental liver fibrosis by attenuating the prooxidant process. Int Immunopharmacol 2015; 28: 244251

[108] Bingul I, Basaran-Kucukgergin C, Aydin AF, Coban J, Dogan-Ekici I, Dogru-Abbasoglu S, Uysal M. Betaine treatment decreased oxidative 
stress, inflammation, and stellate cell activation in rats with alcoholic liver fibrosis. Environ Toxicol Pharmacol 2016; 45: 170-178

[109] Kunnumakkara AB, Bordoloi D, Padmavathi G, Monisha J, Roy NK, Prasad S, Aggarwal BB. Curcumin, the golden nutraceutical: multitargeting for multiple chronic diseases. Br J Pharmacol 2017; 174: 13251348

[110] Aggarwal BB, Harikumar KB. Potential therapeutic effects of curcumin, the anti-inflammatory agent, against neurodegenerative, cardiovascular, pulmonary, metabolic, autoimmune and neoplastic diseases. Int J Biochem Cell Biol 2009; 41: 40-59

[111] Masuda T, Maekawa T, Hidaka K, Bando H, Takeda Y, Yamaguchi H. Chemical studies on antioxidant mechanism of curcumin: analysis of oxidative coupling products from curcumin and linoleate. J Agric Food Chem 2001; 49: 2539-2547

[112] Kaur G, Tirkey N, Bharrhan S, Chanana V, Rishi P, Chopra K. Inhibition of oxidative stress and cytokine activity by curcumin in amelioration of endotoxin-induced experimental hepatoxicity in rodents. Clin Exp Immunol 2006; 145: 313-321

[113] Lin X, Zhang S, Huang R, Wei L, Tan S, Liang S, Tian Y, Wu X, Lu Z, Huang Q. Helenalin attenuates alcohol-induced hepatic fibrosis by enhancing ethanol metabolism, inhibiting oxidative stress and suppressing HSC activation. Fitoterapia 2014; 95: 203-213

[114] Athar M, Back JH, Tang X, Kim KH, Kopelovich L, Bickers DR, Kim AL. Resveratrol: a review of preclinical studies for human cancer prevention. Toxicol Appl Pharmacol 2007; 224: 274-283

[115] Athar M, Back JH, Kopelovich L, Bickers DR, Kim AL. Multiple molecular targets of resveratrol: anti-carcinogenic mechanisms. Arch Biochem Biophys 2009; 486: 95-102

[116] Brasnyo P, Molnar GA, Mohas M, Marko L, Laczy B, Cseh J, Mikolas E, Szijarto IA, Merei A, Halmai R, Meszaros LG, Sumegi B, Wittmann I. Resveratrol improves insulin sensitivity, reduces oxidative stress and activates the Akt pathway in type 2 diabetic patients. Br J Nutr 2011; 106: 383-389

[117] Kundu JK, Surh Y]. Cancer chemopreventive and therapeutic potential of resveratrol: mechanistic perspectives. Cancer Lett 2008; 269: $243-$ 261

[118] Park S], Ahmad F, Philp A, Baar K, Williams T, Luo H, Ke H, Rehmann H, Taussig R, Brown AL, Kim MK, Beaven MA, Burgin AB, Manganiello V, Chung $\mathrm{JH}$. Resveratrol ameliorates aging-related metabolic phenotypes by inhibiting cAMP phosphodiesterases. Cell 2012; 148: 421433

[119] Hong SW, Jung KH, Zheng HM, Lee HS, Suh JK, Park IS, Lee DH, Hong SS. The protective effect of resveratrol on dimethylnitrosamineinduced liver fibrosis in rats. Arch Pharm Res 2010; 33: 601-609

[120] Sebai H, Sani M, Yacoubi MT, Aouani E, Ghanem-Boughanmi N, BenAttia M. Resveratrol, a red wine polyphenol, attenuates lipopolysaccharide-induced oxidative stress in rat liver. Ecotoxicol Environ Saf 2010; 73: 1078-1083

[121] Ahmad A, Ahmad R. Resveratrol mitigate structural changes and hepatic stellate cell activation in N'-nitrosodimethylamine-induced liver fibrosis via restraining oxidative damage. Chem Biol Interact 2014; 221: 1-12

[122] Koneru M, Sahu BD, Gudem S, Kuncha M, Ravuri HG, Kumar JM, Kilari EK, Sistla R. Polydatin alleviates alcohol-induced acute liver injury in mice: relevance of matrix metalloproteinases (MMPs) and hepatic antioxidants. Phytomedicine 2017; 27: 23-32

[123] Domitrovic R, Skoda M, Vasiljev Marchesi V, Cvijanovic O, Pernjak Pugel E, Stefan MB. Rosmarinic acid ameliorates acute liver damage and fibrogenesis in carbon tetrachloride-intoxicated mice. Food Chem Toxicol 2013; 51: 370-378

[124] Shi H, Dong L, Bai Y, Zhao J, Zhang Y, Zhang L. Chlorogenic acid against carbon tetrachloride-induced liver fibrosis in rats. Eur J Pharmacol 2009; 623: 119-124
[125] Shi H, Dong L, Jiang J, Zhao J, Zhao G, Dang X, Lu X, Jia M. Chlorogenic acid reduces liver inflammation and fibrosis through inhibition of tolllike receptor 4 signaling pathway. Toxicology 2013; 303: 107-114

[126] Shi H, Shi A, Dong L, Lu X, Wang Y, Zhao J, Dai F, Guo X. Chlorogenic acid protects against liver fibrosis in vivo and in vitro through inhibition of oxidative stress. Clin Nutr 2016; 35: 1366-1373

[127] Shi A, Shi H, Wang Y, Liu X, Cheng Y, Li H, Zhao H, Wang S, Dong L. Activation of Nrf2 pathway and inhibition of NLRP3 inflammasome activation contribute to the protective effect of chlorogenic acid on acute liver injury. Int Immunopharmacol 2018; 54: 125-130

[128] Yang ZR, Wang HF, Zuo TC, Guan LL, Dai N. Salidroside alleviates oxidative stress in the liver with non- alcoholic steatohepatitis in rats. BMC Pharmacol Toxicol 2016; 17: 16

[129] Zakaria S, Mahmoud AAA, Hasan RA, Mahmoud MF, El Fayoumi HM. Cinnamaldehyde mitigates carbon tetrachloride-induced acute liver injury in rats through inhibition of toll-like receptor 4 signaling pathway. Int J Pharmacol 2016; 12: 851-862

[130] Rahman MM, Muse AY, Khan D, Ahmed IH, Subhan N, Reza HM, Alam MA, Nahar L, Sarker SD. Apocynin prevented inflammation and oxidative stress in carbon tetra chloride induced hepatic dysfunction in rats. Biomed Pharmacother 2017; 92: 421-428

[131] Kim M, Yoo G, Randy A, Kim HS, Nho CW. Chicoric acid attenuate a nonalcoholic steatohepatitis by inhibiting key regulators of lipid metabolism, fibrosis, oxidation, and inflammation in mice with methionine and choline deficiency. Mol Nutr Food Res 2017; 61: 1600632

[132] Sun H, Luo G, Chen D, Xiang Z. A comprehensive and system review for the pharmacological mechanism of action of rhein, an active anthraquinone ingredient. Front Pharmacol 2016; 7: 247

[133] Wu C, Cao H, Zhou H, Sun L, Xue J, Li ], Bian Y, Sun R, Dong S, Liu P, Sun $M$. Research progress on the antitumor effects of rhein: literature review. Anticancer Agents Med Chem 2017; 17: 1624-1632

[134] Zhao YL, Zhou GD, Yang HB, Wang JB, Shan LM, Li RS, Xiao XH. Rhein protects against acetaminophen-induced hepatic and renal toxicity. Food Chem Toxicol 2011; 49: 1705-1710

[135] Lee JH, Jang EJ, Seo HL, Ku SK, Lee JR, Shin SS, Park SD, Kim SC, Kim YW. Sauchinone attenuates liver fibrosis and hepatic stellate cell activation through TGF-beta/Smad signaling pathway. Chem Biol Interact 2014; 224: 58-67

[136] Basnet P, Yasuda I, Kumagai N, Tohda C, Nojima H, Kuraishi Y, Komatsu $\mathrm{K}$. Inhibition of itch-scratch response by fruits of Cnidium monnieri in mice. Biol Pharm Bull 2001; 24: 1012-1015

[137] Liu YW, Chiu YT, Fu SL, Huang YT. Osthole ameliorates hepatic fibrosis and inhibits hepatic stellate cell activation. J Biomed Sci 2015; 22: 63

[138] Schrieber S], Hawke RL, Wen ZM, Smith PC, Reddy KR, Wahed AS, Belle $\mathrm{SH}$, Afdhal NH, Navarro VJ, Meyers CM, Doo E, Fried MW. Differences in the disposition of silymarin between patients with nonalcoholic fatty liver disease and chronic hepatitis C. Drug Metab Dispos 2011; 39: 2182-2190

[139] Wah Kheong C, Nik Mustapha NR, Mahadeva S. A randomized trial of silymarin for the treatment of nonalcoholic steatohepatitis. Clin Gastroenterol Hepatol 2017; 15: 1940-1949

[140] Faghihzadeh F, Adibi P, Rafiei R, Hekmatdoost A. Resveratrol supplementation improves inflammatory biomarkers in patients with nonalcoholic fatty liver disease. Nutr Res 2014; 34: 837-843

[141] Poulsen MK, Sorensen BN, Stodkilde-Jorgensen H, Pedersen SB, GronBaek $\mathrm{H}$, Nielsen $\mathrm{S}$. No effect of long-term high-dose resveratrol on VLDL-TG kinetics, insulin sensitivity, and liver fat content in obese men with nonalcoholic fatty liver disease. Diabetes Obes Metab 2018; 20: 2504-2509

[142] Ting YW, jiang Y, Ho CT, Huang QR. Common delivery systems for enhancing in vivo bioavailability and biological efficacy of nutraceuticals. J Funct Foods 2014; 7 : 112-128 